\title{
Annual Report, Basic Sciences Branch, FY 1990
}

Basic Sciences Branch

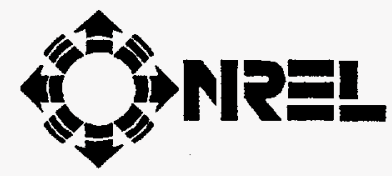

National Renewable Energy Laboratory (formerly the Solar Energy Research Institute) 1617 Cole Boulevard Golden, Colorado 80401-3393

A Division of Midwest Research Institute Operated for the U.S. Department of Energy under Contract No. DE-ACO2-83CH10093

Prepared under Task Non 12$]+201$ 
On September 16, 1991 the Solar Energy Institufe was designated a national laboratory, and its name was changed to the National Renewable Energy Laboratory.

\section{NOTICE}

This report was prepared as an account of work sponsored by an agency of the United States government. Neither the United States government nor any agency thereof, nor any of their employees, makes any warranty, express or implied, or assumes any legal liability or responsibility for the accuracy, completeness, or usefulness of any information, apparatus, product, or process disclosed, or represents that its use would not infringe privately owned rights. Reference herein to any specific commercial product, process, or service by trade name, trademark, manufacturer, or otherwise does not necessarily constitute or imply its endorsement, recommendation, or favoring by the United States government or any agency thereof. The views and opinions of authors expressed herein do not necessarily state or reflect those of the United States government or any agency thereof.

$$
\begin{gathered}
\text { Printed in the United States of America } \\
\text { Available from: } \\
\text { National Technical Information Service } \\
\text { U.S. Depariment of Commerce } \\
\text { 5285 Por Royal Road } \\
\text { Springfield, VA 22161 }
\end{gathered}
$$

Price: Microfiche A01

Printed Copy $\mathrm{AO3}$

Codes are used for pricing all publications. The code is determined by the number of pages in the publication. Information pertaining to the pricing codes can be found in the current issue of the following publications which are generally available in most libraries: Energy Research Abstracts (ERA); Government Reports Announcements and Index (GRA and I); Scientific and Technical Abstract Reports (STAR); and publication NTIS-PR-360 available from NTIS at the above address. 


\section{DISCLAIMER}

Portions of this document may be illegible electronic image products. Images are produced from the best available original document. 


\section{Preface}

This report summarizes the progress of the Basic Sciences Branch of the National Renewable Energy Laboratory (NREL) from October 1, 1989, through September 30, 1990. Six technical sections of the report cover these main areas of NREL's in-house research: Semiconductor Crystal Growth, Amorphous Silicon Research, Polycrystalline Thin Films, III-V High-Efficiency Photovoltaic Cells, Solid-State Theory, and Solid-State Spectroscopy.

Each section of the report was written by the group leader principally in charge of the work. The task in each case was to explain the purpose and major accomplishments of the work in the context of the U.S. Department of Energy's National Photovoltaic Research Program plans.

Volume II of this report contains specific publications produced during FY 1990. These publications are also listed at the end of each section in this report. 


\section{Contents}

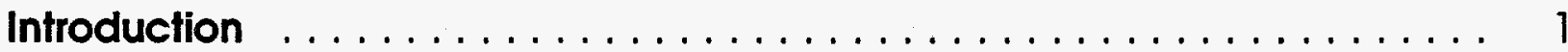

Objectives $\ldots \ldots \ldots \ldots \ldots \ldots \ldots \ldots \ldots \ldots \ldots \ldots \ldots \ldots \ldots$

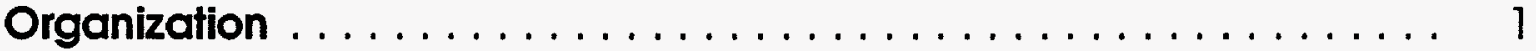

Key Accomplishments $\ldots \ldots \ldots \ldots \ldots \ldots \ldots \ldots \ldots \ldots \ldots$

Crystal Growth Research . . . . . . . . . . . . . . . . . . 1

Amorphous Silicon Research $\ldots \ldots \ldots \ldots \ldots \ldots \ldots \ldots \ldots$

Polycrystalline Thin Films . . . . . . . . . . . . . . . 2

III-V High-Efficiency Photovoltaic Cells . . . . . . . . . . . . 2

Solid-State Theory ........................... 3

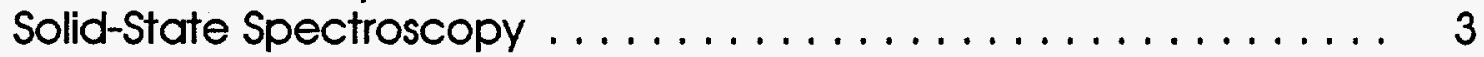

1. Crystal Growth Research $\ldots \ldots \ldots \ldots \ldots \ldots \ldots \ldots \ldots$

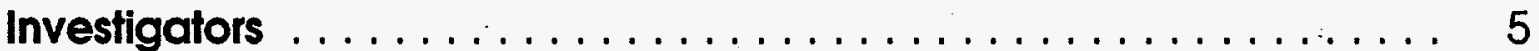

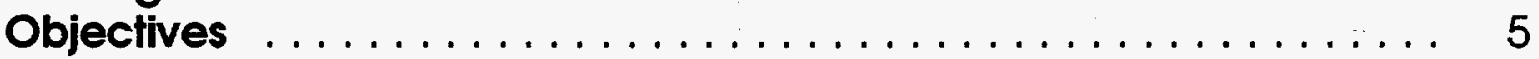

Major Accomplishments ....................... 5

Silicon Crystal Growth . . . . . . . . . . . . . . . . . . . . 5

Germanium Ribbon Substrate Growth for III-V Multijunction

Photovoltaic Cells ......................... 6

Superconductor Materials $\ldots \ldots \ldots \ldots \ldots \ldots \ldots \ldots \ldots$.

Publications and References $\ldots \ldots \ldots \ldots \ldots \ldots \ldots \ldots$

2. Amorphous Silicon Research $\ldots \ldots \ldots \ldots \ldots \ldots \ldots \ldots \ldots \ldots$

Investigators $\ldots \ldots \ldots \ldots \ldots \ldots \ldots \ldots \ldots \ldots \ldots \ldots \ldots \ldots \ldots \ldots \ldots$

Objectives $\ldots \ldots \ldots \ldots \ldots \ldots \ldots \ldots \ldots \ldots \ldots \ldots \ldots \ldots \ldots$

Major Accomplishments . . . . . . . . . . . . . . . . . . . 11

Depositions of Device-Quality, Low-H-Content Amorphous

Silicon . . . . . . . . . . . . . . . . . . . . . . . . . . . . 11

Methods of Improving Glow-Discharge-Deposited a-Si ${ }_{1-x} \mathrm{Ge}_{x}: \mathrm{H}$

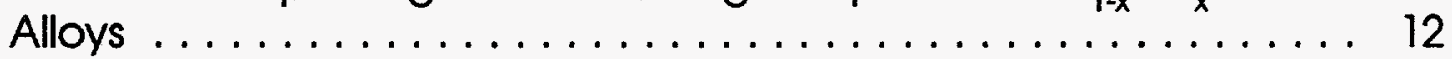

Small-Angle X-Ray Scattering on SiGe Alloys . . . . . . . . . . . 12

Etching Properties of $\mathrm{a}-\mathrm{Si}: \mathrm{H} \ldots \ldots \ldots \ldots \ldots \ldots \ldots$

Defect Equilibrium in Device-Quality a-Si:H and its Relation to Light-Induced Defects . . . . . . . . . . . . . . . 14

Upper Limit to Light-Induced Deuterium Diffusion in

Amorphous Silicon ............................. 15

Electroluminescence in Amorphous Silicon p-i-n Solar Cells . . . . 15

Mobility-Lifetime Products in a-Si:H . . . . . . . . . . . . . . . 16

Diffusion Length Measurements by the Photocarrier

Grating Technique ......................... 16

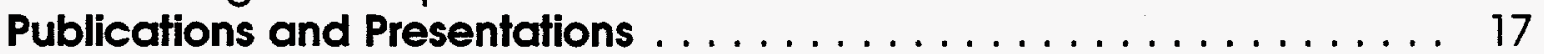




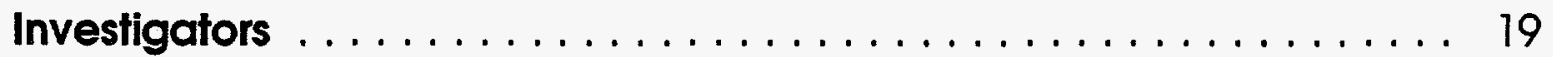

Objectives ........................... 19

Major Accomplishments . . . . . . . . . . . . . . . . . . . . 19

Selenization Process . . . . . . . . . . . . . . . . . . . . 19

Optical and Microstructural Characteristics of $\mathrm{Cu}(\mathrm{In}, \mathrm{Ga}) \mathrm{Se}_{2}$

Polycrystalline Thin Films .................... 21

Microstructural Characterization of Polycrystalline CulnSe $e_{2}$

Thin Films: Ramifications on Device Performance . . . . . . . . . 22

Rapid Thermal Processing of CulnSe ${ }_{2}$ Thin Films . . . . . . . . 23

Publications and References $\ldots \ldots \ldots \ldots \ldots \ldots \ldots \ldots \ldots$

4. III-V High-Efficiency Photovoltaic Cells . . . . . . . . . . . . . . 25

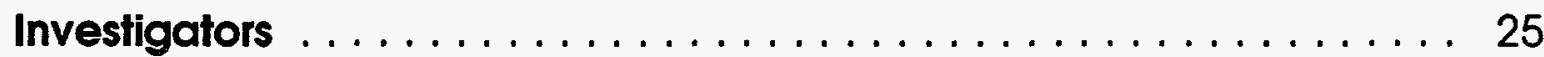

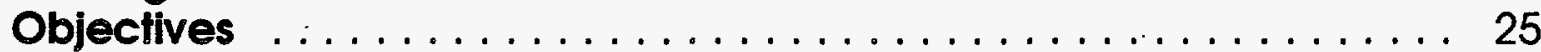

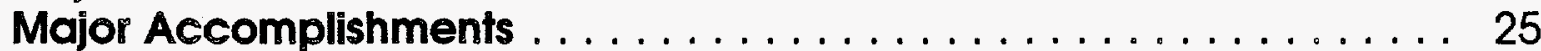

Tandem Cell Modeling . . . . . . . . . . . . . . . . . . . . 25

The Effect of Growth Rate on the Band Gap of GalnP $P_{2} \ldots$. . . . 25

The Photoluminescence of $\mathrm{GaInP}_{2}$ and its Dependence on

Excitation Intensity ........................... 26

Carbon Doping of InP, GaAs, and Related Alloys . . . . . . . . . . 26

Hall Mobility Studies of Ordering in GalnP $\mathrm{P}_{2} \ldots \ldots \ldots \ldots . \ldots . . \ldots 26$

Construction of the New Organometallic Vapor Phase Epitaxy

Growth System . . . . . . . . . . . . . . . . . . . . . 26

Publications and Presentations $\ldots \ldots \ldots \ldots \ldots \ldots \ldots \ldots \ldots$

5. Solid-State theory . . . . . . . . . . . . . . . . . . . . . . . . 29

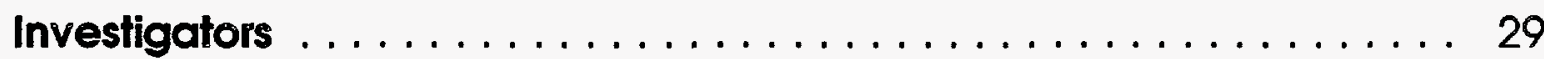

Objectives ........................... 29

Major Accomplishments . . . . . . . . . . . . . . . . . . . . . . . . . 29

Density of States of Random II-VI and III-V Semiconductor Alloys . . 29

Stable Structures and Phase Diagrams of Intermetallic

Compounds ........................... 30

Spontaneous Surface-Induced Long-Range Order in GalnP Alloys . 30

Phase Transition in GaAs/Ge and GaP/Si Alloys . . . . . . . . . . . 31

GaP/GaAs Superlattices ....................... 31

Prediction of Formation Energies of Anti-Phase Boundaries in

AlAs/GaAs ............................ 32

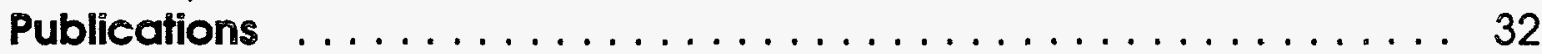

6. Solid-State Spectroscopy $\ldots \ldots \ldots \ldots \ldots \ldots \ldots \ldots \ldots \ldots \ldots$

Investigators $\ldots \ldots \ldots \ldots \ldots \ldots \ldots \ldots \ldots \ldots \ldots \ldots \ldots \ldots \ldots \ldots$

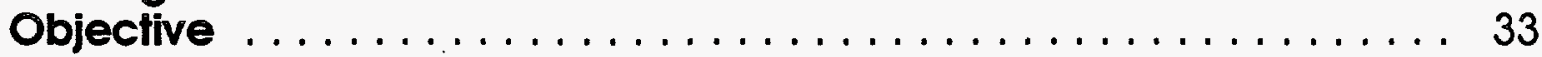


Major Accomplishments . . . . . . . . . . . . . . . . . . . . 33

Modeling the Photoluminescence of Spontaneously

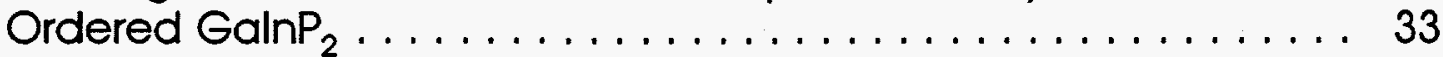

Pioneering Experiments on the Optoelectronic Properties of

Novel Spinodally Decomposed Semiconductor Alloys ........ . 33

Publications and References . . . . . . . . . . . . . . . . . . 35 


\section{Figures}

1-1 Orifice design used for Stepanov growth of Ge ribbons $\ldots \ldots \ldots \ldots 6$

$1-2$ Ge ribbon growing from the melt $\ldots \ldots \ldots \ldots \ldots \ldots$

1-3 Cross-sectional schematic of high-pressure furnace showing internal zero-load temperature profile $\ldots \ldots \ldots \ldots \ldots \ldots \ldots \ldots$

1-4 Profile of actual furnace temperature versus time for a typical fast-cool crystal growth run $\ldots \ldots \ldots \ldots \ldots \ldots \ldots \ldots$

2-1 Urbach edge $\left(E_{0}\right)$ as measured by photothermal deflection spectroscopy

2-2 Quantum efficiency-mobility-lifetime product versus optical band gap for various films

2-3 Void fraction versus momentum transfer for films with and without hydrogen dilution $\ldots \ldots \ldots \ldots \ldots \ldots \ldots \ldots \ldots \ldots \ldots$

2-4 a-Si:H etch rate for various $\mathrm{KOH}$ concentrations using $\mathrm{KOH}-\mathrm{IPA}-\mathrm{H}_{2} \mathrm{O}$ etchants $\left(\mathrm{H}_{2} \mathrm{O} / \mathrm{IPA}=4.74\right.$ by weight $)$

2-5 The two-level configuration coordinate system inferred from this work

2-6 Deuterium SIMS results after 10 days of room-temperature light-soaking

2-7 Maximum of electroluminescence versus voltage on log-log axes . . 16

2-8 Layout of optical components for the photocarrier grating technique

3-1 Selenization apparatus . . . . . . . . . . . . . . . . . . . . . . . . . 20

3-2 X-ray diffraction data showing the formation of indium and $\mathrm{Cu}_{11} \mathrm{ln}$ in sample 706 after vacuum annealing at $200^{\circ} \mathrm{C}$

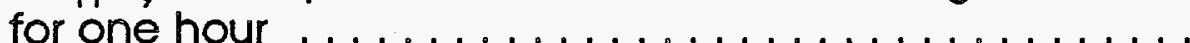

3-3 Optical band gap as a function of gallium and copper content . . . 21

3-4 Microstructural model of polycrystalline thin-film CulnSe $e_{2} \ldots \ldots \ldots 22$ 
3-5 XRD pattern of a co-deposited CulnSe ${ }_{2}$ thin film processed by rapid thermal processing $\ldots \ldots \ldots \ldots \ldots \ldots \ldots \ldots$

4-1 Iso-band-gap contour plot showing the variation of $\mathrm{Ga}_{0.5} \mathrm{In}_{0.5} \mathrm{P}$ band gap with growth rate and growth temperature . . . 26

4-2 The measured Hall mobility for partially ordered and disordered $\mathrm{Ga}_{0.5} \mathrm{In}_{0.5} \mathrm{P}$. The fit to the data includes contributions from the polar optical mobility, a cluster scattering term, and an acoustic deformation potential term . . . . . . . . . . . . . . . . . . 27

6-1 Low-temperature (15 K) PL spectra from the sample excited with light polarized perpendicular to the modulation and parallel to 


\section{Introduction}

This report covers the research and development in the Basic Sciences Branch at the National Renewable Energy Laboratory (NREL) during the period from October 1, 1989, to September 30, 1990.

\section{Objectives}

The primary objectives of the branch are twofold: (1) to define and carry out fundamental and applied research on state-of-the-art photovoltaic materials and devices that are consistent with the Department of Energy's (DOE) five-year research plans, and (2) to complement subcontract research activities. Additional objectives are to identify research needs and to develop, evaluate, and transfer a coherent base of scientific knowledge and technology to the public and private sectors, so that rational decisions can be made on the relevance of different technologies for cost-effective power generation.

\section{Organization}

Consistent with these objectives, research activities within the branch are structured into the following program areas: Semiconductor Crystal Growth, Amorphous Silicon, Polycrystalline Thin Films (involving group II-VI compounds and their analogues), III-V High-Efficiency Photovoltaic Cells, Solid-State Theory, and Solid-State Spectroscopy. The scope of each of these program areas was chosen carefully to ensure a close integration with research activities conducted outside NREL, including subcontracted research. The bulk of the work discussed here is a continuation of the work discussed in our prior annual reports. In addition to its mainstream activities, the branch also conducts research on high-critical-temperature superconducting thin films and bulk materials and research on electrochromic materials. The superconductivity work is funded by DOE's Office of Energy Storage and Distribution. The work on electrochromic materials for "smart window" applications is supported by the DOE Office of Building Technologies. The branch also conducts solidstate theoretical research supported by DOE's Office of Energy Research/Basic Energy Sciences (OER/BES). In fiscal year (FY) 1990, the branch staff was composed of 31 full-time and 15 visiting scientists and students.

\section{Key Accomplishments}

During FY 1990, the members of the branch made major contributions to various technologies through fundamental studies and applied research and development. A brief overview of some of the key accomplishments is given here. More extensive discussions and publication lists are given in the following sections.

\section{Crystal Growth Research}

The Crystal Growth Research Group's activities during FY 1990 focussed on three areas: (1) the growth of elemental semiconductors such as $\mathrm{Si}$ and $\mathrm{Ge}$ in both single-crystal and ribbon form, (2) new facilities for growing single-crystal CuInSe ${ }_{2}$ and its quaternary alloys, and (3) the growth of hybrid semiconductor/superconductor structures. Some key accomplishments follow.

- We grew a series of deliberately carbon-doped, but otherwise high-purity, float-zoned (FZ) silicon crystals with carbon contents up to $7 \times$ $10^{16} \mathrm{~cm}^{-3}$ to establish the role of impurities in controlling the minority carrier lifetime. We also supplied samples of pure FZ silicon with various self-interstitial and vacancy microdefects to private industry for photovoltaic research and development.

- We attempted, with limited success, to use radio-frequency shaping for the contactless growth of silicon ribbon crystals. We demonstrated the process of growing Ge ribbons directly from the melt (i.e., the Stepanov method) as a potentially low-cost means of obtaining Ge substrates for the epitaxial growth of GaAs.

- We finished designing, fabricating, and testing a prototype system for growing chalcopyrite semiconductors and alloys by a liquidencapsulated directional solidification method.

- We completed an exploratory study on the fabrication of a monolithic hybrid superconductor/semiconductor device. The target device structure was an n-type silicon substrate with p-type thallium-diffused bifacial layers forming a $\mathrm{p}-\mathrm{n}-\mathrm{p}$ device with a $\mathrm{TIBaCaCuO}$ superconducting surface on one side of the silicon. Numerous attempts failed to produce a viable hybrid structure.

\section{Amorphous Silicon Research}

During FY 1990, the Amorphous Silicon Research Group fócussed on two areas: (1) developing an improved deposition method for amorphous silicon and its alloys, and (2) understanding and 
reducing light-induced degradation in amorphoussilicon solar cells. Some of the accomplishments follow.

- We deposited, characterized, and compared the properties of two sets of hydrogenated amorphous silicon (a-Si:H) films deposited by glow discharge (GD) and hot wire (HW) processes. The study showed that the structure of the low-hydrogencontent HW films exhibits better ordering than that of comparable GD films, and that the superior electronic properties of these HW films are largely a result of these structural improvements.

-We used small-angle $x$-ray scattering to study the microstructural properties of a-Si:Ge alloys. We found that hydrogen dilution has a much greater effect on the microstructure than on the transport properties. However, the changes depend on the particular deposition method being used. For example, radio-frequency GD deposition leads to an increase in the void density, whereas the directcurrent GD deposition leads to a decrease in the void density. The a-Si:Ge:H alloy films have a much larger void density than that of the a-Si:H films.

- Based on the unique etching properties of a-Si:H, we patented two new ion-beam lithography techniques that use an a-Si:H film as the inorganic resist. The selective etching required for the lithographic processes is achieved by either preferentially etching a-Si: $\mathrm{H}$ with higher hydrogen content or by preferentially etching a-Si: $\mathrm{H}$ versus $\mathrm{SiO}_{\mathrm{x}}$

- Secondary ion mass spectroscopy (SIMS) measurements to study the thermal and light-induced diffusion of deuterium (D) in a-Si:H showed no observable light-induced $D$ diffusion at room temperature or at $130^{\circ} \mathrm{C}$. This result suggests a light-induced D hopping rate of less than $10^{-2} \mathrm{~s}^{-1}$ and constrains models of hydrogen involvement in the Staebler-Wronski effect.

- We set up a steady-state photocarrier grating technique to measure the ambipolar diffusion length in a-Si:H films. Preliminary data indicate that the diffusion length ranges from 500 to $2000 \AA$ with a measurement accuracy of better than $10 \%$.

\section{Polycrystalline Thin Films}

Work in the Polycrystalline Thin Films Group concentrated on two closely related lines of study:

(1) material fabrication and characterization; and

(2) device fabrication, characterization, and modeling.

Some of the major accomplishments in these areas follow.
- We conducted a detailed study on the phase behavior-and microstructure of sequentially evaporated indium/copper layer stacks (as precursors for subsequent selenization) deposited on molybdenum-coated glass substrates. Using Auger spectrometry and $x$-ray diffraction studies, we determined both the equilibrium and nonequilibrium phases that can exist under different processing conditions.

- Within the framework of an experimental design matrix that involves a number of deposition parameters, we studied the optical and microstructural properties of polycrystalline $\mathrm{CuIn}_{1-\mathrm{y}} \mathrm{Ga}_{\mathrm{y}} \mathrm{Se}_{2}$ thin films deposited by coevaporation. We determined the optical band gaps of near-stoichiometric and copper-poor films and established a functional relationship between the two.

- We studied the microstructure and morphology of polycrystalline thin-film CuInSe ${ }_{2}$ with copper content ranging from 17 to 32 at. \%. We proposed a microstructural model that suggests that the inter-granular microstructure is dominated by $\mathrm{Cu}_{2-\delta} \mathrm{Se}$ precipitation at the grain boundaries and free surfaces of CuInSe ${ }_{2}$.

- We achieved the formation of polycrystalline thin-film $\mathrm{CuInSe}_{2}$ by rapid thermal processing of co-evaporated copper, indium, and selenium. We formed nearly single-phase material from co-deposited precursors with a post-deposition annealing time of less than two minutes, and we achieved enhanced grain growth $(\sim 100 \mu \mathrm{m})$.

\section{III-V High-Efficiency Photovoltaic Cells}

The primary objectives of III-V high-efficiency photovoltaic cell research are (1) conducting research leading to an understanding of the problems inherent in fabricating high-efficiency cascade cells, and (2) developing new approaches and ideas to solve these problems. Specific accomplishments follow.

-We completed a theoretical study showing the sensitivities of various one-, two-, and threejunction III-V tandem cell efficiencies to variations in spectral content and temperature. The study shows that high-band-gap cells are sensitive to air mass and turbidity, while lowband-gap cells are sensitive to temperature and atmospheric water vapor.

- We studied the dependence of the $\mathrm{GaInP}_{2}$ band gap on the growth rate and growth temperature; the dependence is shown to be quite complex. We studied the photoluminescence 
spectrum of $\mathrm{GaInP}_{2}$ as a function of excitation intensity; we observed a blue shift with increasing excitation intensity, the magnitude of which depends on growth conditions and substrate orientation. We believe that the shift results from imperfect ordering, yielding a structure consisting of ordered domains distributed within a disordered matrix.

- We studied $\mathrm{CCl}_{4}$ as a p-type dopant, for GaAs and related compounds, as a function of various growth conditions. We found that $\mathrm{CCl}_{4}$ is an excellent doping source for GaAs grown by metal-organic chemical vapor deposition. However, in the case of $\mathrm{GaInP}_{2}$, the electrical quality of the carbon-doped film was significantly lower than that of zinc-doped material, and hole concentration could not be increased above $10^{17} \mathrm{~cm}^{-3}$.

\section{Solid-State Theory}

The primary mission of the Solid-State Theory Group involves three areas: (1) bringing state-of-the-art methods and ideas of condensed matter theory into the realm of photovoltaic materials, (2) developing a fundamental understanding of the elements that constitute and enhance solar cell performance, and (3) using this knowledge to design novel photovoltaic materials. The research in this group is partially funded by OER/BES. Some of the key accomplishments in this area follow.

- We developed a novel design method called "special quasirandom structure" and used it to calculate the electronic density of states, charge densities, equilibrium bond lengths, and optical bowing parameters of several group II-VI and III-V semiconductor alloys that are important for photovoltaic applications.

- We used the density functional formalism with a simple configurational search strategy to establish a direct link between the electronic structure and phase stability of a number of intermetallic alloys. A ground-states search revealed that the Ptx (where $\mathrm{x}=\mathrm{Ni}, \mathrm{Cu}, \mathrm{Rh}$, or $\mathrm{Pd}$ ) intermetallics will form stable ordered structures at low temperature, whereas the previous model predicted them to phase separate.

- We applied the first-principles pseudopotential method to study the energetics of several surface atomic arrangements of a single GaIn $\mathrm{P}_{2}$ layer on a GaAs substrate. We found that among the fully relaxed, dimerized $\mathrm{GaInP}_{2}$ surfaces, the surface corresponding to the experimentally $\mathrm{Cu}-\mathrm{Pt}$-like three-dimensional order is favored.

- We performed first-principles pseudopotential calculations for the structural properties, band offsets, and single-particle electronic states of $(\mathrm{GaP})_{\mathrm{n}}(\mathrm{GaAs})_{\mathrm{n}}(001)$ and (111) superlattices (where $\mathrm{n} \leq 3$ ). Calculations show that the monolayer $(\mathrm{GaAs})_{1}(\mathrm{GaP})_{1}$ superlattice of either of these orientations is indirect if constrained epitaxially on a substrate whose lattice constant is $a(0.5)$. However, if grown coherently on a GaAs substrate, we predict that both of these superlattices will have a direct gap.

\section{Solid-State Spectroscopy}

Our research in solid-state spectroscopy focussed on two areas: (1) modeling the photoluminescence of spontaneously ordered $\mathrm{GaInP}_{2}$ alloys using the formalism of quantum statistics, and (2) pioneering experiments on the optoelectronic properties of novel spinodally decomposed semiconductor alloys. Some of the highlights follow.

- We performed investigations into the polarized photoluminescence of spontaneously ordered $\mathrm{GaInP}_{2}$ breaking of cubic symmetry in the band structure of this alloy. We used the formalism of quantum statistics to provide a quantitative description of the observed luminescence.

- Our studies on a $(\mathrm{GaP})_{2} /(\mathrm{InP})_{2}$ superlattice grown on a (001) GaAs substrate provided the first experimental demonstration of a spontaneously generated lateral superlattice formed by spinodal decomposition. 
Section 1

\section{Crystal Growth Research}

\section{Investigators}

T. F. Ciszek, Principal Scientist

C. R. Schwerdtfeger, Associate Scientist

J. Alleman, Staff Scientist

T. Schuyler, Master Technician (through

November 1989)

R. Burrows, Master Technician (from January 1990)

C. Sarris, Part-Time Temporary

\section{Objectives}

The objectives of this research were to (1) develop controlled impurity doping of carbon in high-purity, single-crystal, dislocation-free silicon; (2) develop contactless shaping for silicon ribbon growth;

(3) demonstrate Ge ribbon growth; (4) advance our capabilities in growing single-crystal CuInSe ${ }_{2}$ and its alloys with $\mathrm{Ga}$ partially replacing In; (5) conduct a Director's Development Fund (DDF) project for forming hybrid semiconductor/superconductor structures; and (6) complete a DDF project on bulk and singlecrystal superconductors.

\section{Major Accomplishments}

\section{Silicon Crystal Growth}

Ingot Growth. We carried out a number of activities related to silicon ingot crystallization. We gave invited presentations at the semiannual Japanese government MITI Sunshine Project Review and at several Japanese companies on "Float-Zoning and Electromagnetic, Cold-Container Silicon Crystal Growth and Characterization." Under intensive development in Japan's MITI-NEDO Sunshine Project is electromagnetic continuous casting of silicon for photovoltaics (PV) use. This is the process described in the Department of Energy's (DOE) U.S. patent 4,572,812 (1986) and originated at the National Renewable Energy Laboratory (NREL). We are now making 85-mm-square ingots.

We generated a series of deliberately carbon-doped, but otherwise high-purity, float-zoned (FZ) silicon crystals with carbon contents up to $7 \times 10^{16} \mathrm{~cm}^{-3}$; these will be used in impurity studies. We also provided samples of pure FZ material with various selfinterstitial and vacancy microdefects to silicon PV commercial companies for research purposes.
Silicon Ribbon Growth. We attempted to use radio frequency (RF) shaping for contactless growth of silicon ribbon crystals. The shaping effect is based on Ampere's law, which states that the repulsive force per unit length between two parallel wires carrying currents in opposite directions is proportional to the product of the two currents and inversely proportional to the separation of the wires. In our case, the two current-carrying objects are a single-turn, elongated $R F$ coil and a ribbon-shaped meniscus of silicon melt contained within the coil opening. The inner surface of the RF coil carries an alternating current $(2 \mathrm{MHz})$, which induces a current to flow in the melt and keeps it molten (internal resistive heating). The induced current travels on the outer skin of the melt and is, at any instant in time, traveling in an opposite direction to the current that induced it. Thus, by Ampere's law, there is a repulsive force tending to push the melt away from the coil. This force can be tailored by shaping the coil so as to produce a ribbon-shaped melt meniscus. However, there is also a strong surface tension force, which tends to make the melt circular in cross-section.

At RF current levels commensurate with ribbon solidification, a simple oblong inner coil opening did not produce strong enough shaping forces to overcome the surface tension force. We attempted to enhance the shaping force by bringing the inner surface of the coil closer to the melt at the middle area of the long sides and farther from the melt near the two ends. We also attempted to increase the shaping force by increasing the RF current. To do this without overheating the solidifying solid/liquid interface, we placed a watercooled, rectangular shorting ring above the RF coil. The RF coil and shorting ring were used for pulling ribbons vertically upward (i.e., feed rod below the coil and solidified ribbon above). We were not able to achieve an aspect ratio of width to thickness higher than 2.1 in equilibrium growth (at an equilibrium width of $5.5 \mathrm{~mm}$ ). 


\section{Germanium Ribbon Substrate Growth For III-V Multijunction Photovoltaic Cells}

Recent advances in III-V multijunction solar cells resulted in power conversion efficiencies on the order of $30 \%$. These cells have been based on gallium arsenide substrates that also serve as the active lower cell component. Because there is some concern about the economics of GaAs substrates for large-scale PV applications, germanium has been investigated as a substrate. Germanium has a reasonably good lattice match with GaAs. However, Ge wafers are also rather costly. We explored the feasibility of growing $\mathrm{Ge}$ ribbons directly from the melt as a potentially less costly means of obtaining Ge substrates, but this was only a cursory or "feasibility"-type study.
We chose the von Gomperz method [von Gomperz, 1922], perhaps better known as the Stepanov method [Tsivinskii and Stepanov, 1965], of shaped ribbon growth because of the availability of a very compatible shaping material-graphite. In this method, a nonwetting orifice is placed on the top, free surface of the melted material and shapes the liquid meniscus from which the ribbon is solidified. Because of its extensive use as a crucible material for ingot growth of Ge, graphite is known to be a non-contaminating substance for liquid Ge. Figure 1-1 shows the orifice design we used. It and the crucible were made from Poco DFP graphite. We mounted the orifice plate independently on a graphite holder so that it could be positioned vertically relative to the crucible. We employed induction heating at $360 \mathrm{kHz}$ with feedback power

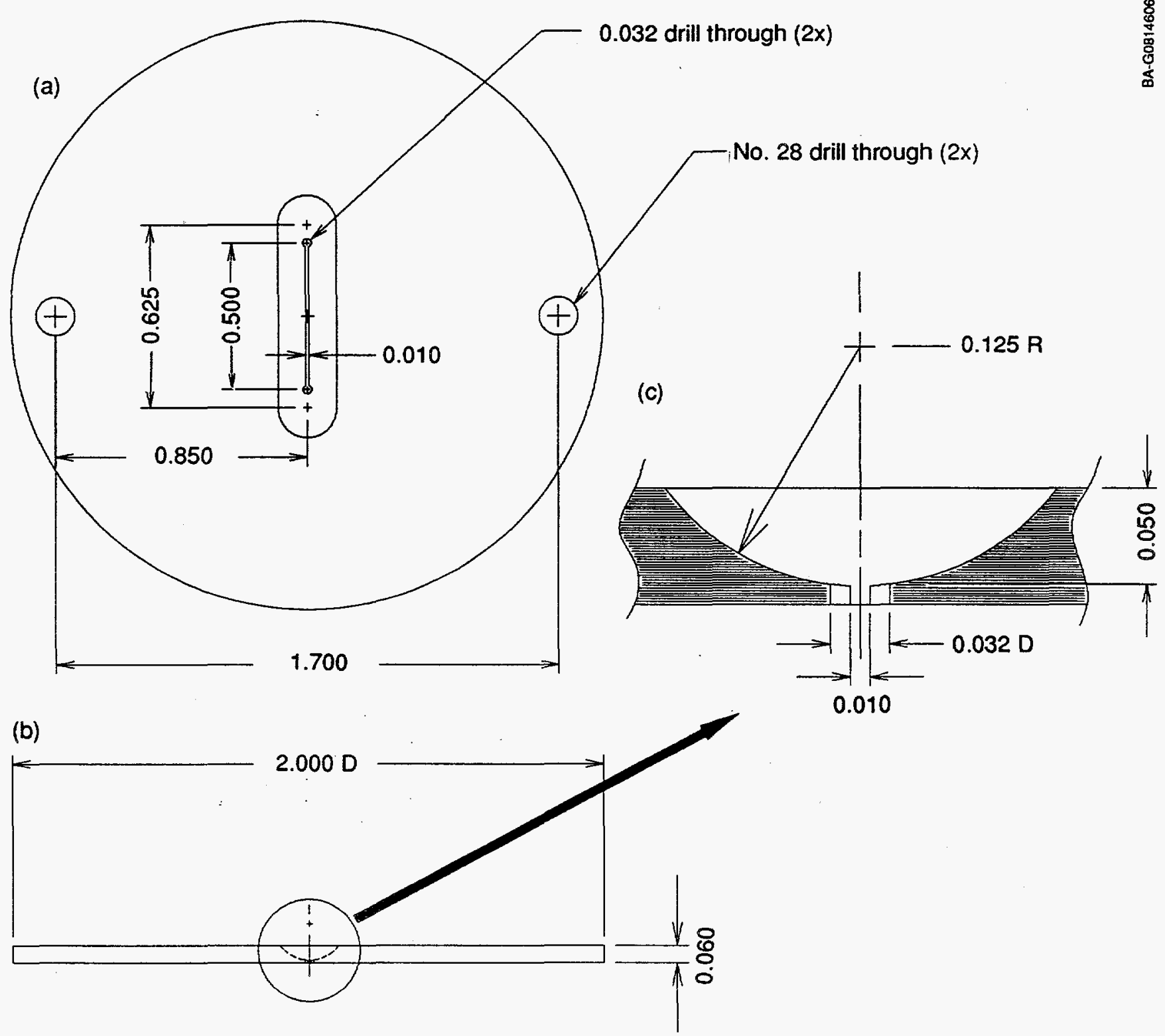

Figure 1-1. Orifice design used for Stepanov growth of Ge ribbons. (a) top view, (b) side view, (c) enlarged side vlew. All units in Inches. 
control based on the crucible temperature. A singlecrystal seed cut from a Ge polished wafer was mounted on a vertical pulling mechanism that could be aligned with the orifice slot.

Figure 1-2 shows Ge ribbon growth in progress. The bright orifice disc can be seen on a dark Ge melt (due to emissivity and reflection). On the diameter of the disc, the two dark dots represent liquid $\mathrm{Ge}$ in the holes at the ends of the orifice slot. The ribbon is growing vertically between the holes (occupying about $1 / 3$ of the slot in this photo). The dark vertical rod to the right of the Ge ribbon is the graphite orifice holder. We grew 4-mm-wide Ge ribbons that were $0.39-\mathrm{mm}$ thick. Relatively few problems were encountered in the feasibility demonstration, and we believe that ribbon widths up to $20 \mathrm{~mm}$ could be achieved quite easily. Unlike dendritic web growth, in which only (111) crystallographic surfaces can be obtained, any surface orientation should be feasible with the shaping technique described here.

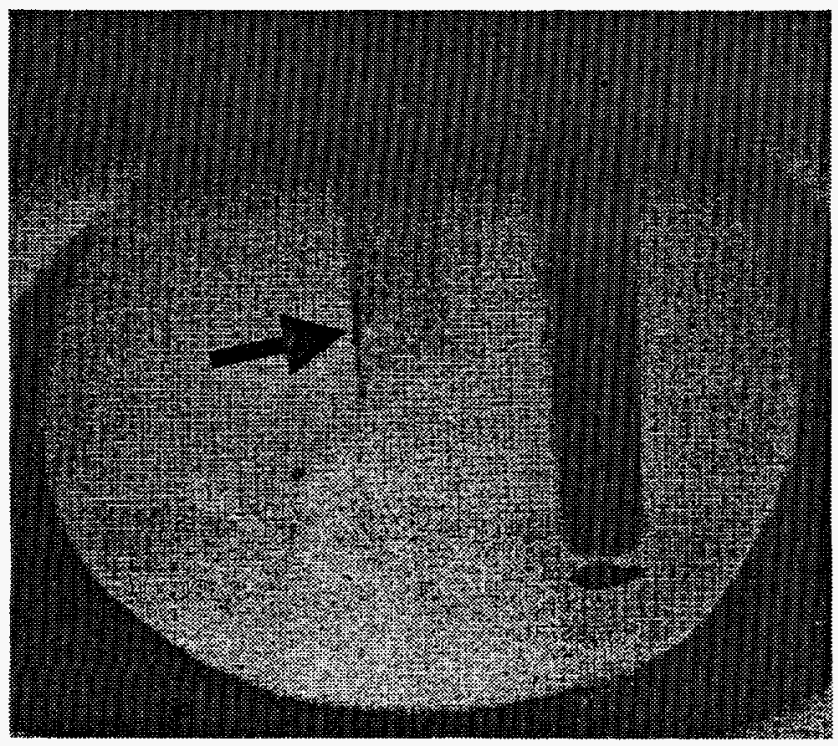

Figure 1-2. Ge ribbon growing from the melt

\section{Compound Semiconductor Crystal Growth}

Background. Because of the nature of the material, growing compound chalcopyrite semiconducting crystals often requires special techniques. We developed a computer-controlled high-pressure furnace system to specifically utilize these special techniques. Thus, a liquidencapsulated directional solidification method will be used for growing chalcopyrite semiconductors and alloys. The system was detailed in the Solid State Photovoltaic Research Branch FY 1989 Annual Report, so this report will focus on system improvements and results of the first four runs.
First, we present a brief description of the process. Elemental copper, indium, and selenium are placed in stoichiometric ratios in a 22-mm (inside diameter) quartz ampoule along with boric oxide (which acts as the encapsulant). The ampoule and its contents are then heated to about $1100^{\circ} \mathrm{C}$ and are allowed to melt completely. The boric oxide forms a molten layer above the rest of the material. This molten layer, and 40-60 bars of argon over pressure, help prevent the selenium vapors from escaping the melt (the vapor pressure of selenium at $1200^{\circ} \mathrm{C}$ is about 40 Bars). From this point, there are two possible growth techniques: (1) moving the ampoule down through a temperature gradient to solidify at a specific rate, or (2) slowly reducing the furnace temperature while maintaining the ampoule in a fixed position. As the material cools, large grains of CuInSe, form. Under proper conditions, crack-free grains larger than $1 \mathrm{~cm}$ should be attainable. Cracking is a problem, as are electronic and compositional uniformity. All of these problems will be addressed en route to making good crystals.

Prototype System. When contemplating building a new system with three chambers, three pulling mechanisms, three heaters, and three control systems, it seems logical to build a prototype. This allows some debugging and troubleshooting prior to building a complete system. With this in mind, we built and successfully tested a prototype pulling mechanism. We constructed the rack with three stepper motor indexers and three power supplies. We also installed and tested the prototype cooling system. The last step was to set up the software to control this prototype system.

After some debugging, leak checking (and fixing), and minor modifications, the prototype furnace and chamber were ready for testing. The next step was to determine the temperature profile of the resistive heater in the chamber. This became a rather lengthy process. A good temperature profile for this system might have a flat region in which to melt the material and a gradient in which to lower the ampoule. After the profile was determined for a given heater, a new heater was designed and built. Then, it was annealed (to allow for operation at $1200^{\circ} \mathrm{C}$ ) and a new profile was determined. After several designs, we obtained a satisfactory profile. The chamber seemed to be secure, the pulling mechanism worked, the computer controlled the heater and stepper motor, and a useable temperature profile had been produced. The prototype system was now ready for a few quick test runs with real material.

Test Runs. The first test run (CIS001) was merely a short test of the control software and the pulling mechanism. Set to be five days long, this first run was designed to allow a maximum of $12^{\circ} \mathrm{C}$ per hour cooling that the growing crystal would experience at 


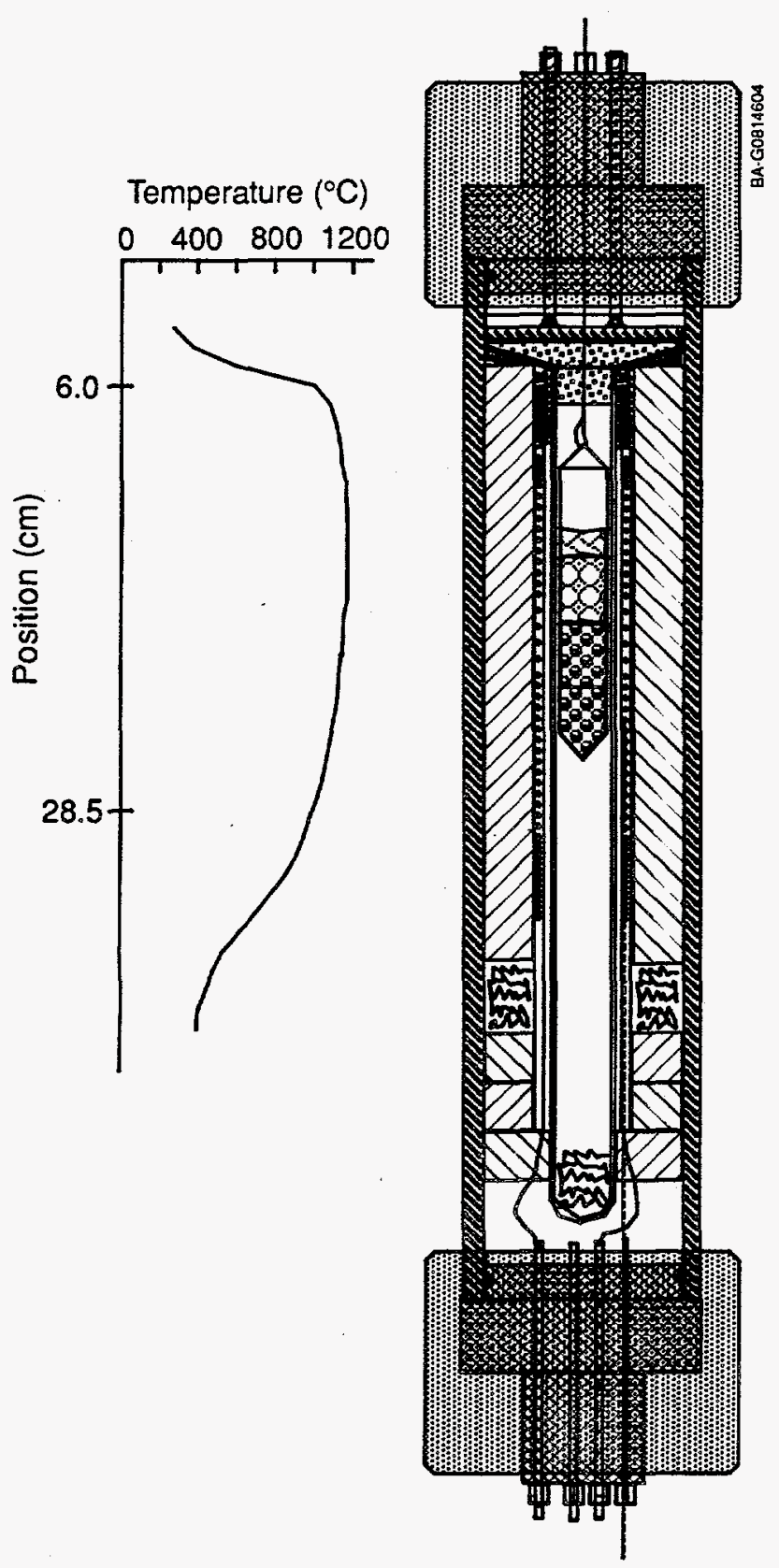

selenium. However, the initial chemical ratios included 3 at. \% selenium to avoid this situation. Electron microprobe analysis did show an excess of about $1 \%-2 \%$ selenium, so the conductivity type is apparently determined by other factors in addition to composition.

Analyzing the first run, we determined that the software needed some minor revising. The stainlesssteel shaft also showed signs of deterioration. When we removed the sample from the chamber, we noticed that the shaft was not connected to the ampoule. Exactly when this happened is uncertain. The small grain size could be attributed to one of at least three factors: (1) the poor temperature control, (2) the shaft contamination, or (3) the ampoule falling from the shaft prior to solidification.

The second run (CISO02) was done under identical conditions as CIS001 except that we added $2 \%$ excess selenium rather than $3 \%$ and modified the software for smoother temperature control. Figure 1-4 shows the temperature versus time plot for the run.

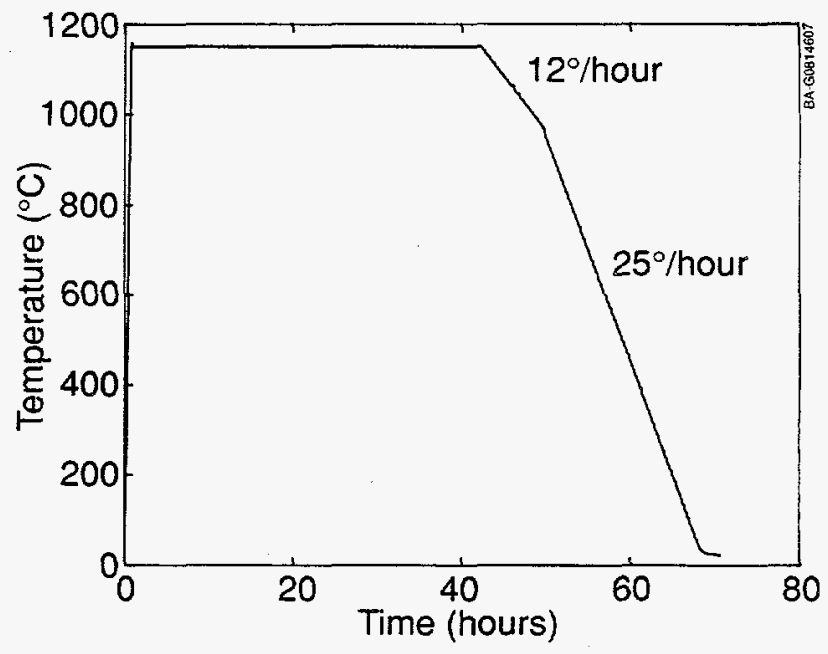

Figure 1-3. Cross-sectional schematic of highpressure furnace showing infernal zero-load temperature profile

any point during the run. The temperature profile versus position in the chamber is shown in Figure 1-3.

As it turned out, the first run showed some bugs in the software that had not been apparent in shorter dry trial runs. In spite of having to manually ramp down the furnace (instead of using the predetermined ramping program), the material solidified into one solid ingot about $7 \mathrm{~cm}$ long and $22 \mathrm{~mm}$ in diameter. The ingot had no visible cracks but, upon slicing, showed relatively small grains $(<0.5 \mathrm{~mm})$. The entire ingot was p-type, which suggests a deficiency of

Figure 1-4. Profile of actual furnace temperature versus time for a typical fast-cool crystal growth run

The resultant ingot was about the same size as that produced in CISO01, but it had many large cracks on the first-to-freeze (FF) end. The cracking was so severe that the sample fell apart in that region when we attempted to slice it on the diamond saw. This end of the ingot was all p-type. The last-to-freeze (LF) end had fewer visible cracks and was sliceable. The crosssection revealed several large grains on the order of $5 \mathrm{~mm}$ across. This section was all n-type.

Analyzing the second run, we found that the software worked better but still needed some changes. Overall, the results were much better than those of the first run. 
We felt confident that a repeat run would confirm that the process produces large grains.

We set up the third run (CISO03) to cool at $10^{\circ} \mathrm{C} / \mathrm{h}$ but left all other settings the same as in CISO02. The resulting ingot had small grains and few cracks (very similar to that of CIS001) and was all p-type (also like that of CISO01). The boric oxide was more noticeable (more brown in color) than in the other two runs. This could indicate more contamination from the shaft, or it could indicate that more selenium is escaping the melt but remaining in the boric oxide. Again, the ampoule was not connected to the shaft after the run (as in CIS001).

Analyzing the third run, we determined that the software was working very well (with a new version installed). We did not know when the ampoule fell off the shaft, so we could not clearly identify the reason for such small grains. We decided that another run with a new shaft may help eliminate the contamination.

We set up the fourth run (CISO04) to be an exact replica of CIS003 but with a new stainless-steel shaft. Unfortunately, the ampoule fell from the shaft again, and the run yielded small grains that were p-type on the FF end and nearly all p-type on LF end with a few small n-type regions. The boric oxide was brownishblue in color but not quite as dark as in CISOO3.

Analyzing the fourth run, we found that the temperature control from the system was working very well, as was the pulling mechanism. It became obvious that the canthal wire used to support the ampoules becomes brittle when cooled and tends to break at some point. It will be necessary to try other support materials and perhaps another shaft material as well.

At this point, we designed, built, annealed, and profiled five more heating cores. Some had flat regions in which to melt the material, while others had shallow gradients to be used for gradient freeze growth where the ampoule remained fixed.

We modified the software to include over-temperature protection in the event that a control thermocouple should burn out. Without this, the computer sends full power to a furnace with a bad thermocouple until the heater core melts down.

There are a few other modifications to be made, but the prototype testing is over; it's time to scale up to three chambers. The prototype was put together safely but hastily. We will construct the new system with safety, reliability, repeatability, and neatness as top priorities.
In fiscal year (FY) 1991, we will perform the following tasks:

- Complete the cooling water system for three chambers

- Complete the high-pressure gas delivery system to all three chambers

- Complete the pulling mechanisms for three chambers

- Complete software modifications for three chambers

- Complete the profiles for heaters in three chambers

- Complete the safety interlocks on the pulling mechanism and the water cooling system

- Begin experimental runs, picking up where CIS004 left off.

\section{Superconductor Materials}

Bulk Materials. Our earlier work involving melt processing of $\mathrm{YBa}_{2} \mathrm{Cu}_{3} \mathrm{O}_{7-\delta}$ and $\mathrm{Bi}_{2} \mathrm{Sr}_{2} \mathrm{CaCu}_{2} \mathrm{O}_{8}$ bulk superconductors was done in a horizontal, largediameter, uniform hot-zone furnace configuration similar to that used for semiconductor wafer diffusion. In FY 1990, we built two vertical furnaces. We intended to use one with silicon carbide heating elements to investigate how higher melting temperatures $\left(1250^{\circ}-1400^{\circ} \mathrm{C}\right)$ would affect superconductor properties. This furnace, and one with a Canthal A-1 heating element, also provided the opportunity to further identify growth parameters in vertical furnaces as opposed to horizontal systems like the diffusion furnace. One benefit is that the scientist is able to see the reaction occurring in the crucible.

We found that several factors played critical roles, and others more nominal roles, in determining the properties of bulk $\mathrm{Bi}_{2} \mathrm{Sr}_{2} \mathrm{CaCu}_{2} \mathrm{O}_{8}$ solidified from melted mixed oxides. The critical condition seems to be the annealing step. Each sample is melted in a crucible, cooled to room temperature, and then sliced into disk-like samples. Each sample is then annealed at $860^{\circ} \mathrm{C}$. A sample $22 \mathrm{~mm}$ in diameter and $4 \mathrm{~mm}$ thick requires six hours of annealing to fully convert the material to the superconducting product. The ramp up and ramp down are not important and may even be instantaneous. The best ambient is air. An $\mathrm{O}_{2}$-rich ambient does not seem to be noticeably beneficial. The initial melting and mixing of powders is not critical. The powders can be melted quickly and cooled quickly and will still produce a good sample. The sample can remain at the melted temperature for any length of time and then be cooled. Some samples were melted and then cooled a few minutes later; others were held at the melt temperature overnight. The melt temperature may vary from $1000^{\circ}$ to $1250^{\circ} \mathrm{C}$ with no adverse affect on the sample. Hence, the important factors are the melt temperature (which must be above $1000^{\circ} \mathrm{C}$ ) and the annealing time (which must be at least six hours). 
We also continued to provide single-crystal samples of $\mathrm{YBa}_{2} \mathrm{Cu}_{3} \mathrm{O}_{7-\delta}, \mathrm{ErBa}_{2} \mathrm{Cu}_{3} \mathrm{O}_{7-\delta}$ and $\mathrm{Bi}_{2} \mathrm{Sr}_{2} \mathrm{CaCu}_{2} \mathrm{O}_{8}$ to university researchers for a variety of joint research studies.

Monolithic Hybrid Superconductor/Semiconductor Materials. The research on this project had two objectives: (1) to demonstrate a simple monolithic hybrid superconductor/semiconductor device, and (2) to introduce a toxicologically safe operation procedure for working with the thallium-based superconductors at NREL. The target device structure was an n-type silicon substrate with p-type $\mathrm{Tl}$ diffused bifacial layers forming a $p-n-p$ device and with a $\mathrm{TIBaCaCuO}$ superconducting surface on one surface of the silicon. The materials for the superconducting layer (less $\mathrm{Tl}$ ) were deposited by an inductively coupled plasma torch process. Trivial selective etching would allow for removing localized areas to make a simple device such as a diode.

Before beginning the experiments, we developed safe operating procedures (SOPs) for superconducting material preparation, plasma deposition, and thallium diffusion.

We used a 5-kW RF generator operating at $28 \mathrm{MHz}$ and an accompanying inductively coupled plasma torch, in conjunction with an existing chamber. We used a mixture of argon and hydrogen as the chamber atmosphere, at atmospheric pressure. During deposition, a positive flow of the argon/hydrogen mixture was started and carried away heat from the torch and ionized material. The original design called for ablation of a pellet target with the substrate next to the target. We found that this produced a slow deposition rate and limited compositions to $\mathrm{CuO}$. The pellet was formed through a sintering process; the superconductor precursor $\mathrm{BaCaCuO}$ was mixed from oxide powders to be barium-rich because we found barium to be the most volatile element of the composition. We then pressed the powder into a pellet and sintered it in a furnace at $800^{\circ} \mathrm{C}$ for three hours. We then reground and sintered it again before using it as a target in the chamber.

We obtained the best deposition rate by feeding a fine powder through the center of the plasma torch directly into the plasma. Our feeder design used a fluidized bed with a take-off tube in the center of a cloud of powder particles, and it delivered a stream of the powder at a controlled particle density and flow rate. Our typical feed rate was a few mg per minute. We controlled substrate heating by varying the proximity of the substrate to the plasma. We typically heated the substrate to a temperature of around $600^{\circ} \mathrm{C}$. The morphology of the deposited film consisted of small particles stuck together to make a film that was amorphous rather than crystalline (as we had hoped).
The deposition rate was below $50 \AA$ per minute. Numerous attempts failed to reduce a viable hybrid semiconductor/superconductor with either the Tlbased system or the Bi-based superconductors.

The $\mathrm{Tl}$ diffusion process required using a complex containment system for safety because of the toxic hazard involved with thallium. We loaded the substrates in an ampoule with a small pocket in the end for thallium oxide. We then sealed the ampoule. The ampoule is thick-walled quartz and was strong enough to contain the thallium when vaporized. The sealed ampoule was contained in a high-temperature alloy steel chamber to contain any shards should the ampoule rupture. We placed the chamber and ampoule in a furnace that had flowing oxygen and two bubbler traps at the exhaust of the furnace to precipitate out any thallium vapor should the ampoule rupture. The exhaust from the bubblers was then sent out through a toxic-rated exhaust vent.

The process for depositing superconductor precursor films via an inductively coupled plasma torch did not work as anticipated. The primary problem was the difficulty of controlling the stoichiometry of the superconducting precursor during deposition. The diffusion of thallium into the precursor film and silicon substrate was also unsuccessful. A superconductive film was not produced, but we did show that a buffer layer was needed to stop destructive diffusion between the superconductor and silicon. The physical structures of the films were not uniform because of the nature of the deposition process.

We achieved some success in inductively coupled plasma deposition of thin multicrystalline silicon on graphite substrates. The grain size was small (on the order of $1 \mu \mathrm{m})$. We did not determine if the grain size could be increased to a usable size.

\section{Publications and References}

\section{Publications Included in Volume II}

T. F. Ciszek, R. Schwerdtfeger, and C. D. Evans, "Liquid-Phase Formation of Bi-Sr-Ca-Cu-O Superconducting Wires and Sheets," J. Crystal Growth 104, 1990, pp. 136-141.

\section{References}

E. von Gomperz, "Single-Crystal Wires," Z. Physik. 8, 1922, p. 184.

S. V. Tsivinskii and A. V. Stepanov, "Growth of Germanium Single Crystals of Controlled Shape," Soviet Phys.-Solid State 7, 1965, pp. 1, 148. 


\section{Section 2}

\section{Amorphous Silicon Research}

\section{Investigators}

R. Crandall, Principal Investigator

and Group Leader

H. Branz, Senior Scientist

H. Mahan, Senior Scientist

T. McMahon, Senior Scientist

B. Nelson, Associate Scientist

S. Tsuo, Senior Scientist

E. Molenbroek, Visiting Scientist

M. Vanecek, Visiting Scientist

I. Balberg, Visiting Scientist

S. Salamon, Visiting Scientist

Y. Xu, Research Technician

D. Tanenbaum, Visiting Scientist

M. Silver, Visiting Scientist

\section{Objectives}

During FY 1990, the Amorphous Silicon Research Group concentrated on two areas: (1) improved deposition methods to improve both hydrogenated amorphous silicon (a-Si:H) and its alloys, and

(2) reducing the light-induced degradation of a-Si: $\mathrm{H}$.

It is important to make advances in both of these areas

if stable solar cells with higher efficiencies are to be made. We made significant contributions in both areas. In addition, we developed a new ion-beam lithography technique based on the different etch rates of hydrogenated and non-hydrogenated amorphous silicon. The construction of a new diffusion-length measuring technique has also enhanced our productivity.

A significant improvement in material quality was made using decomposed process gas on a hot filament (i.e., the "hot wire" [HW] process). Our technique produces both a-Si:H and a-SiGe:H materials that are superior to those produced by the standard glow discharge (GD) method. In addition, HW films of a-Si:H are more resistant to light-induced defect production. We are developing methods to incorporate these films in devices. There is a widespread belief that hydrogen dilution of the source gases leads to improved a-SiGe:H alloys produced by GD deposition. We systematically investigated this through both transport and structure characterizations and concluded that any improvements are marginal and depend more on the deposition system.

Our understanding of the light-induced metastable defects continues to improve. With more under- standing, we find that the phenomenon is more complex. However, we are refining our models and experiments to restrict the number of possible causes of the degradation.

A brief account of some achievements of the Amorphous Silicon Research Group follows.

\section{Major Accomplishments}

\section{Depositions of Device-Quality, Low-H-Content Amorphous Silicon}

We deposited, characterized, and compared the properties of two sets of a-Si:H films. One set was deposited by the traditional GD process, and the other was deposited by the HW process, in which we varied the substrate temperature $\left(T_{s}\right)$ from $40^{\circ}$ to $630^{\circ} \mathrm{C}$ to vary the $\mathrm{H}$ content from 27.0 to 0.1 at. \%. Our analytical measurements included infrared (IR) spectroscopy ( $\mathrm{H}$ bonding), photothermal deflection spectroscopy (Urbach edge), optical absorption (band gap), photo- and dark conductivity, the steady-state photocarrier grating technique (ambipolar diffusion length), and electron spin resonance (ESR) (spin density). Results of the Urbach edge behavior for both HW and GD films are shown in Figure 2-1. Although we found no discernible behavior differences in GD and $\mathrm{HW}$ films with $\mathrm{H}$ contents greater than 10 at.\% (deposited at $\mathrm{T}_{\mathrm{s}}<200^{\circ}-300^{\circ} \mathrm{C}$ ), the low-H-content $\mathrm{HW}$ films are quite superior (electronically and structurally) to GD films with comparable $\mathrm{H}$ contents. In particular, device-quality a-Si:H containing as little as $1 / 10$ the bonded $\mathrm{H}$ observed in device-quality $\mathrm{GD}$ films has 
been deposited by the HW technique. These low-Hcontent (1-4 at. \%) HW films exhibit a photoconductivity as high as $10^{-5}(\Omega \mathrm{cm})^{-1}$, an Urbach edge of $50 \mathrm{mV}$, a light-to-dark conductivity ratio greater than $10^{5}$, a band gap of $1.67 \mathrm{eV}$, an ambipolar diffusion length as high as $1650 \AA$, and a spin density less than $1.3 \times 10^{16} \mathrm{~cm}^{-3}$. Several indications suggest that the structure of the low-H-content HW films exhibits better ordering than that of comparable GD films, and that the superior electronic properties of these HW films are due in part to these structural improvements.

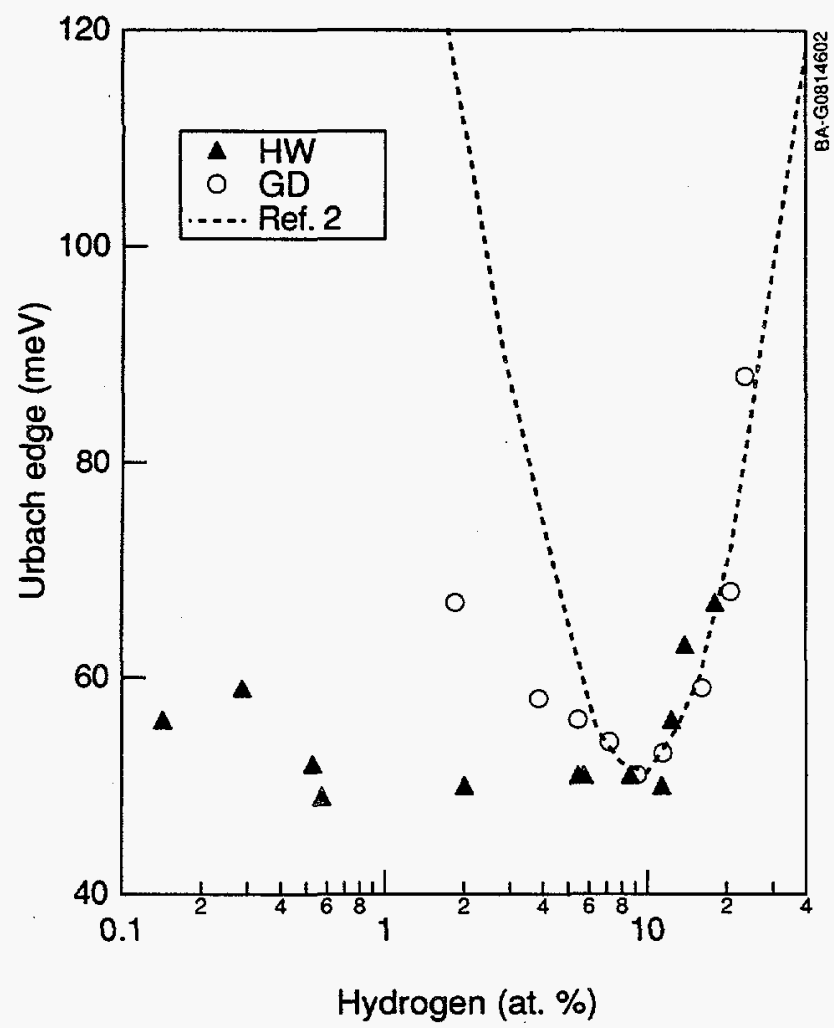

Figure 2-1. Urbach edge $\left(E_{\circ}\right)$ as measured by phofothermal deflection spectroscopy. Reference 2 refers to a compllation of literature data tabulated by M. Stutzmann (Phil. Mag B 60, 1989, p. 531).

\section{Methods of Improving Glow-Discharge-Deposited a-Si $i_{1-x} G_{x}: H$ Alloys}

We studied methods of improving RF GD-deposited $\mathrm{a}-\mathrm{Si}_{1-x} \mathrm{Ge}_{\mathrm{x}}$ alloys (with $\mathrm{x}$ varying from 0 to 1 ) deposited using silane and germane gas mixtures. The material processing methods we studied include (1) increasing $\mathrm{T}_{\mathrm{s}}$ during deposition, (2) post-deposition annealing and hydrogenation, (3) diluting the process gas by hydrogen, argon, or helium, and (4) varying the process gas pressure during deposition. The film properties we studied include $\mathrm{Ge}$ and $\mathrm{H}$ contents, photosensitivity, quantum efficiency-mobility-lifetime $(\eta \mu \tau)$ product, conductivity activation energy, photoluminescence (PL) intensity, film deposition rate, ambipolar diffusion length (L) determined by the photocarrier grating technique, and microstructure determined by small-angle x-ray scattering (SAXS).

We found that hydrogen dilution reduces the $\mathrm{Ge}$ content and thus increases the optical band gap $\left(E_{g}\right)$ of the deposited film. Comparing films with the same $E_{g^{\prime}}$ but with a slightly improved $L$ and microstructure, we found that hydrogen dilution (up to $80 \%$ ) has no significant effect on other properties. Figure 2-2 shows the $\eta \mu \tau$ product versus $\mathrm{E}_{\mathrm{g}}$ for a-SiGe:H deposited

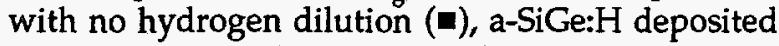
with hydrogen dilution $(x)$, and a-Si:H deposited with varying $H$ content $(\bullet)$. Helium dilution of the process gas yields slightly better results than hydrogen dilution and much better results than argon dilution.

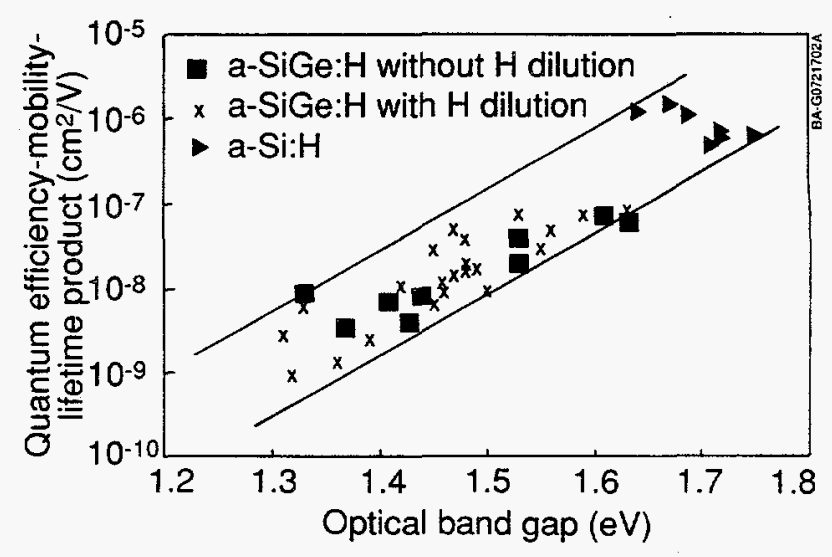

Figure 2-2. Quantum efficiency-mobility-lifetime product versus optical band gap for various films

The etch rate of a-Ge:H in a hydrogen plasma was found to be negligible compared to that of $a-S i: H$. This difference in etching properties may contribute to the poor electronic properties of a-SiGe:H. Increasing $\mathrm{T}_{s}$ (up to $280^{\circ} \mathrm{C}$ ) increases the amount of $\mathrm{Ge}-\mathrm{H}$ bonds in the film even though it decreases the total $\mathrm{H}$ content. The PL intensity of a-SiGe:H films plotted versus $\mathrm{E}_{g}$ shows an anomalous peak at about $1.5 \mathrm{eV}$.

\section{Small-Angle X-Ray Scattering on SiGe Alloys}

Considerable work was devoted to improving the transport properties of a-SiGe:H alloys used as the red absorbing $\mathrm{p}-\mathrm{i}-\mathrm{n}$ structure in multijunction solar cells. Research is currently concentrating on hydrogen dilution of the source gas to improve the alloy. Because microstructure is linked to film quality, we made detailed measurements of the voids using SAXS.

We found that hydrogen dilution has a much larger effect on the microstructure than on the transport. However, the changes depend on the deposition system. For our RF GD deposition system, there is an increase in the void density with hydrogen dilution, whereas for films produced by direct current (DC) GD deposition there is a decrease in the void density with 


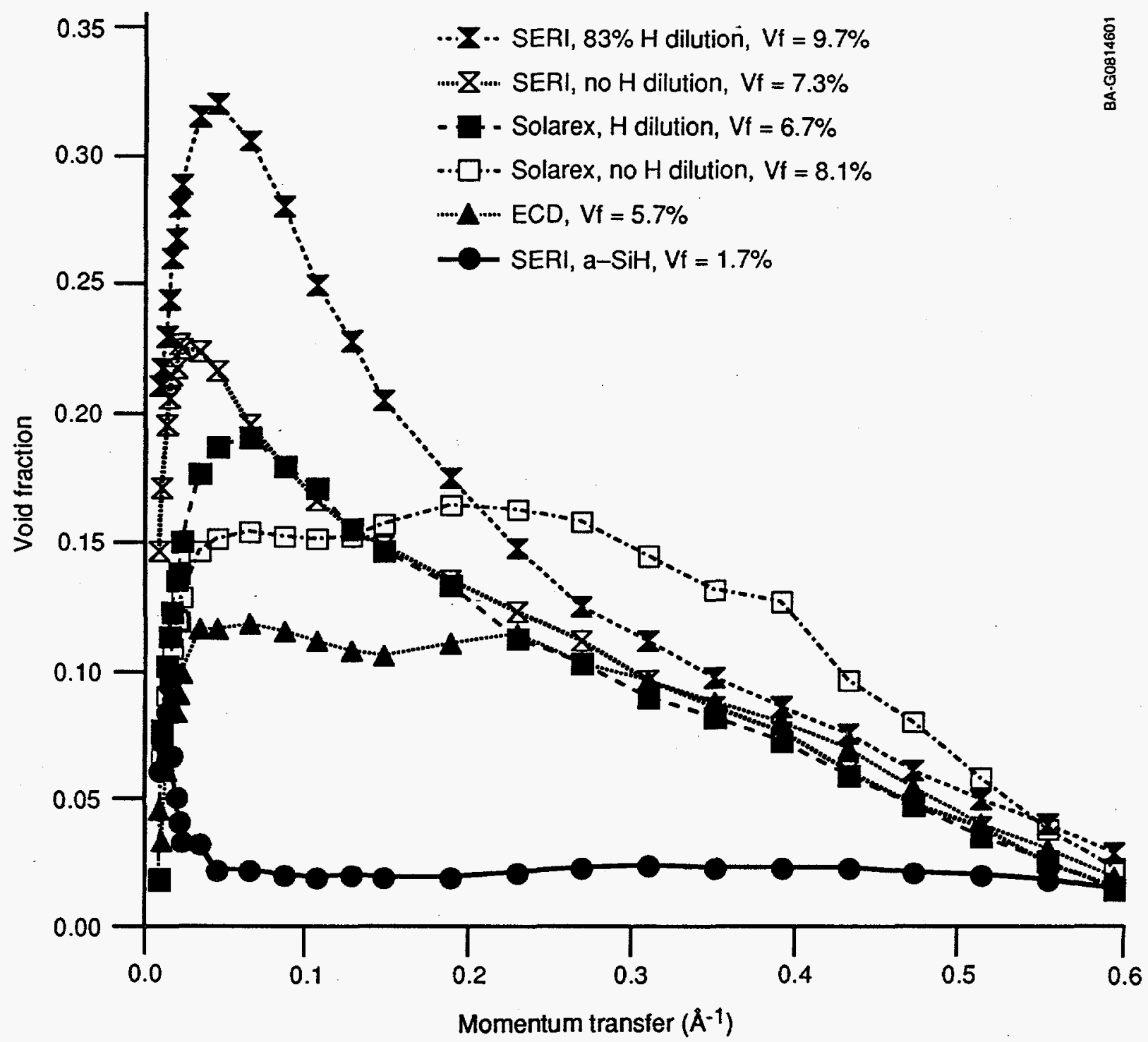

Figure 2-3. Void traction versus momentum transfer for films with and without hydrogen dilution. The optical band gap of all the films is $1.5 \mathrm{eV}$. The "ECD" film was grown by RF glow-discharge deposition of a mixture of $\mathrm{SiF}_{4}, \mathrm{GeH}_{4}$, $\mathrm{SiH}_{4}$, and $\mathrm{H}_{2}$ by Energy Conversion Devices (ECD). The "Solarex" films were grown by direct-current glow-discharge deposition of a mixture of $\mathrm{GeH}_{4}$, $\mathrm{SiH}_{4}$, and $\mathrm{H}_{2}$ by Solarex Corporation.

hydrogen dilution. Figure 2-3 presents the void fraction versus momentum transfer (h) for different films of a-SiGe:H compared to a-Si:H. $h^{-1}$ is roughly proportional to the radius of a spherical microvoid.

The a-SiGe:H shows considerably more scattering than the a-Si: $\mathrm{H}$, indicating both larger and more microvoids. A similar deterioration of transport properties with increasing void fraction (Vf) is also observed for a-Si:H.

\section{Etching Properties of a-Si:H}

We studied wet chemical and dry etching properties of doped and undoped a-Si:H films with bonded hydrogen content varying from 0 to 20 at. \%. The etching processes we studied include (1) wet chemical etching using solutions of $\mathrm{KOH}$, isopropyl alcohol (IPA), and $\mathrm{H}_{2} \mathrm{O}$, (2) hydrogen plasma etching, (3) $\mathrm{XeF}_{2}$ vapor etching, and (4) hydrogen ion-beam etching. The wet chemical etch rate of undoped a-Si:H in a $\mathrm{KOH}$-based etchant depends very strongly on both the $\mathrm{KOH}$ concentration in the solution and on the hydrogen content of the film. Figure 2-4 shows the wet chemical etch rate versus $\mathrm{KOH}$ (in wt. \%) for a-Si films with no hydrogen $\left(E_{g}=1.50 \mathrm{eV}\right.$, upper curve) and a-Si:H films with 6.5 at. \% hydrogen $\left(E_{g}=1.70 \mathrm{eV}\right.$, lower curve). The etchants we used were mixtures of $\mathrm{KOH}, \mathrm{IPA}$, and $\mathrm{H}_{2} \mathrm{O}$ with $\mathrm{H}_{2} \mathrm{O} / \mathrm{IPA}=4.74$ by weight. The wet chemical etch rate of a-Si:H in a KOH-IPA$\mathrm{H}_{2} \mathrm{O}$ solution with $36 \mathrm{wt}$.\% $\mathrm{KOH}$ can be controlled 
from 10 to $90 \mathrm{~nm} / \mathrm{min}$ by varying the hydrogen content of the film. We found that the etch rate of a-Si:H in an RF hydrogen plasma decreases linearly with increasing hydrogen content. The RF hydrogen plasma etching is very sensitive to the existence of native oxides on the surface of a-Si:H. Hydrogen ion-beam etching is less sensitive to surface oxides. The etch rate of a-Si:H depends more strongly on the ion-beam current density than on energy. $\mathrm{XeF}_{2}$ vapors at a pressure of 0.1 torr spontaneously etch $1.75-\mathrm{eV}$-band-gap a-Si:H films at a fast rate of $3 \mathrm{~nm} / \mathrm{s}$ with the sample at room temperature. Phosphorus-doped a-Si:H has etching properties similar to those of undoped a-Si:H. However, boron-doped $\mathrm{a}-\mathrm{Si}: \mathrm{H}$ and $\mathrm{a}-\mathrm{SiC}: \mathrm{H}$ have much smaller wet chemical and hydrogen plasma etch rates than those of undoped a-Si:H. Similar etch-rate dependencies on the Fermi level position have been observed in other semiconductors.

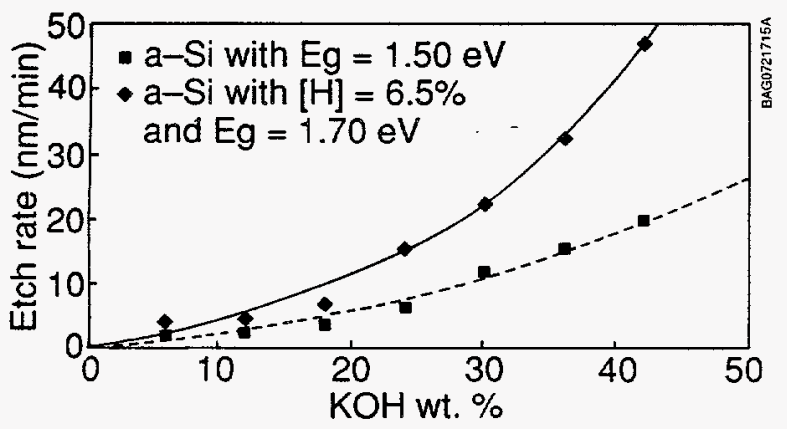

Figure 2-4. a-Sl:H etch rate for various $\mathrm{KOH}$ concentrations using $\mathrm{KOH}-\mathrm{IPA}-\mathrm{H}_{2} \mathrm{O}$ etchants $\left(\mathrm{H}_{2} \mathrm{O} / \mathrm{IPA}=4.74\right.$ by weight)

Based on the unique etching properties of a-Si:H, we patented two new ion-beam lithography techniques that use an a-Si:H film as the inorganic resist. The selective etching required for the lithographic processes is achieved by either preferentially etching a-Si:H with higher hydrogen content or by preferentially etching a-Si:H versus $\mathrm{SiO}_{x}$.

\section{Defect Equilibrium in Device-Quality a-Si:H and its Relation to Light-Induced Defects}

We measured ESR data on thermal equilibrium spin concentrations from room temperature to $280^{\circ} \mathrm{C}$ for a 60-pm-thick, device-quality a-Si:H film. The two-level energy configuration coordinate diagram shown in Figure 2-5 summarizes defect and annealing results. The figure shows a defect formation energy of $0.35 \mathrm{eV}$ in material with $1 \times 10^{15} \mathrm{~cm}^{-3}$ spins at $190^{\circ} \mathrm{C}$; the two-level configuration coordinate diagram would then have a "source" density of $10^{19} \mathrm{~cm}^{-3}$.

The relaxation of spin densities, $N_{s}\left(t_{A}\right)$, were fitted to a stretched exponential relaxation time dependence of the following form:

$$
N_{s}\left(t_{A}\right)=\left(N_{i}-N_{f}\right) e^{-\left(t_{A} / \tau\right)^{\beta}}+N_{f},
$$

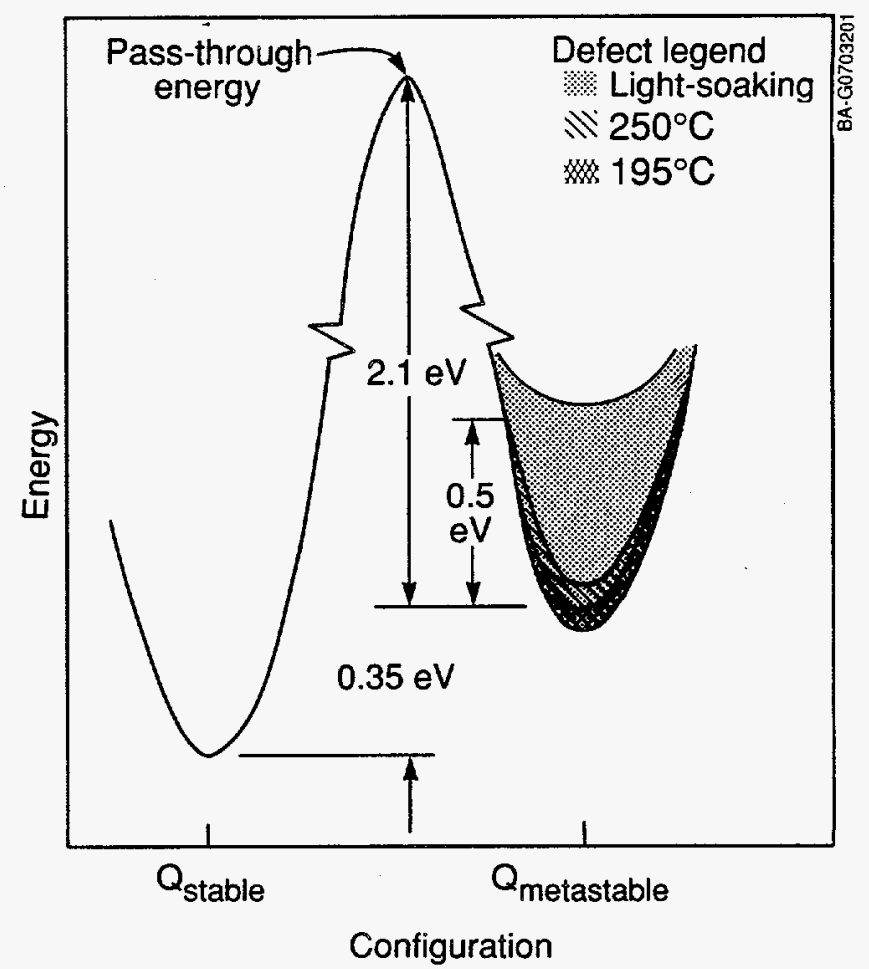

Figure 2-5. The two-level configuration coordinate system inferred from this work. Metastable populations are shown for light-soaking and fast cooling ( $F C$ ).

where $N_{i}$ is the initial quenched-in density, $N_{f}$ is the final annealing value at $t_{A}=\infty, \tau$ is the time constant, and $\beta$ is the stretch factor. Annealing time constants of defects quenched in from $250^{\circ} \mathrm{C}$ are thermally activated between $150^{\circ}$ and $190^{\circ} \mathrm{C}$ with an activation energy of $2.1 \mathrm{eV}$.

One $150^{\circ} \mathrm{C}$ annealing sequence was carried out from a quench temperature of $190^{\circ} \mathrm{C}$ : the defects introduced at the higher temperature anneal faster; the metastable states with higher formation energies have smaller annealing activation energies. The thermally induced defects "fill" the metastable side of the two-level system shown in Figure 2-5. As the "well" is filled, the additional states become easier to anneal. Defects quenched in from $250^{\circ} \mathrm{C}$ occupy states $0.040 \mathrm{eV}$ higher than defects quenched in from $190^{\circ} \mathrm{C}$, as depicted.

Differences in the anneal kinetics and saturation levels of light-soaking and thermal defects can be explained even if the same two-level system of Figure 2-5 is used to describe both. Defects created by thermal equilibrium processes correspond to a Boltzmann distribution of the low-lying, fairly stable metastable configurations characteristic of $\mathrm{kT}=0.04 \mathrm{eV}$. In contrast, light-induced metastable states can produce higher formation energy defects because of the higher recombination energy available from optical excitation. 
Light-induced defects have a $0.5-\mathrm{eV}$ smaller annealing barrier resulting from one of two processes: (1) In a non-equilibrium trapping model, once the recombination energy converts the metastable defect, it could be considered inactive and "stuck" (unable to relax further or anneal because the temperature is too low) with a large number of relatively unstable, non-equilibrium metastable defects. (2) Alternately, a high-temperature equilibrium model allows the defect further reconfiguration as if the thermal excitation that converted it in the first place were equivalent to a very hightemperature source with an equivalent $\mathrm{kT}$ of $0.5 \mathrm{eV}$. Defects included within the quasi-Fermi level splitting can convert and equilibrate. These configurations would fill higher states in the "well," as shown in Figure 2-5.

\section{Upper Limit to Light-Induced Deuterium Diffusion in Amorphous Silicon}

We used secondary ion mass spectrometry (SIMS) measurements to study thermal and light-induced $D$ diffusion in undoped a-Si:H(1000 $\AA) / \mathrm{a}-\mathrm{Si}: \mathrm{H}: \mathrm{D}(1000 \AA)$ / a-Si:H(5000 $\AA) / c-S i$ sandwich structures. Thermal diffusion coefficients are consistent with previous measurements, but light-induced D diffusion is not observed at any temperature. We can place an upper limit of $10^{-18} \mathrm{~cm}^{2}-\mathrm{s}^{-1}$ on the room-temperature $D$-diffusion coefficient induced by the absorption of $10^{22} \mathrm{~cm}^{-3}-\mathrm{s}^{-1}$ red photons. A one-hour light soak in this beam reduces the photoconductivity of the sandwich to $11 \%$ of its initial value, a significant light-induced degradation.
During illumination, we shaded half of the sample to produce a control with the same thermal history as the light-soaked sample. Figure 2-6 shows measured D profiles. Broadening may result from non-ideal a-Si:H/a-Si:H:D interfaces or collisional mixing during the SIMS measurement. There is no observable lightinduced $\mathrm{D}$ diffusion at room temperature or at $130^{\circ} \mathrm{C}$. The calculated ten-day diffusion profiles shows that a diffusion coefficient of $\mathrm{d}=10^{-18} \mathrm{~cm}^{2}-\mathrm{s}^{-1}$ would be clearly observable. This result suggests a light-induced $D$ hopping rate of less than $10^{-2} \mathrm{~s}^{-1}$ and constrains models of hydrogen involvement in the StaeblerWronski effect.

\section{Electroluminescence in Amorphous Silicon p-i-n Solar Cells}

To better understand the physics of recombination in a-Si:H p-i-n solar cells, we studied the electroluminescence (EL) under forward bias. Because electrons and holes are injected from opposite sides of the sample, we are able to probe non-geminate radiative and non-radiative recombination processes. We studied both the voltage- and temperature-dependence of the EL. As shown in Figure 2-7, we found that the effective generation rate is proportional to the square of the applied voltage. This suggests that the radiative recombination rate is proportional to the doubleinjection electron density [Wang et al., 1991].

We analyzed the data to find that the non-radiative lifetime of electrons is temperature- and voltagedependent. However, the radiative lifetime at constant

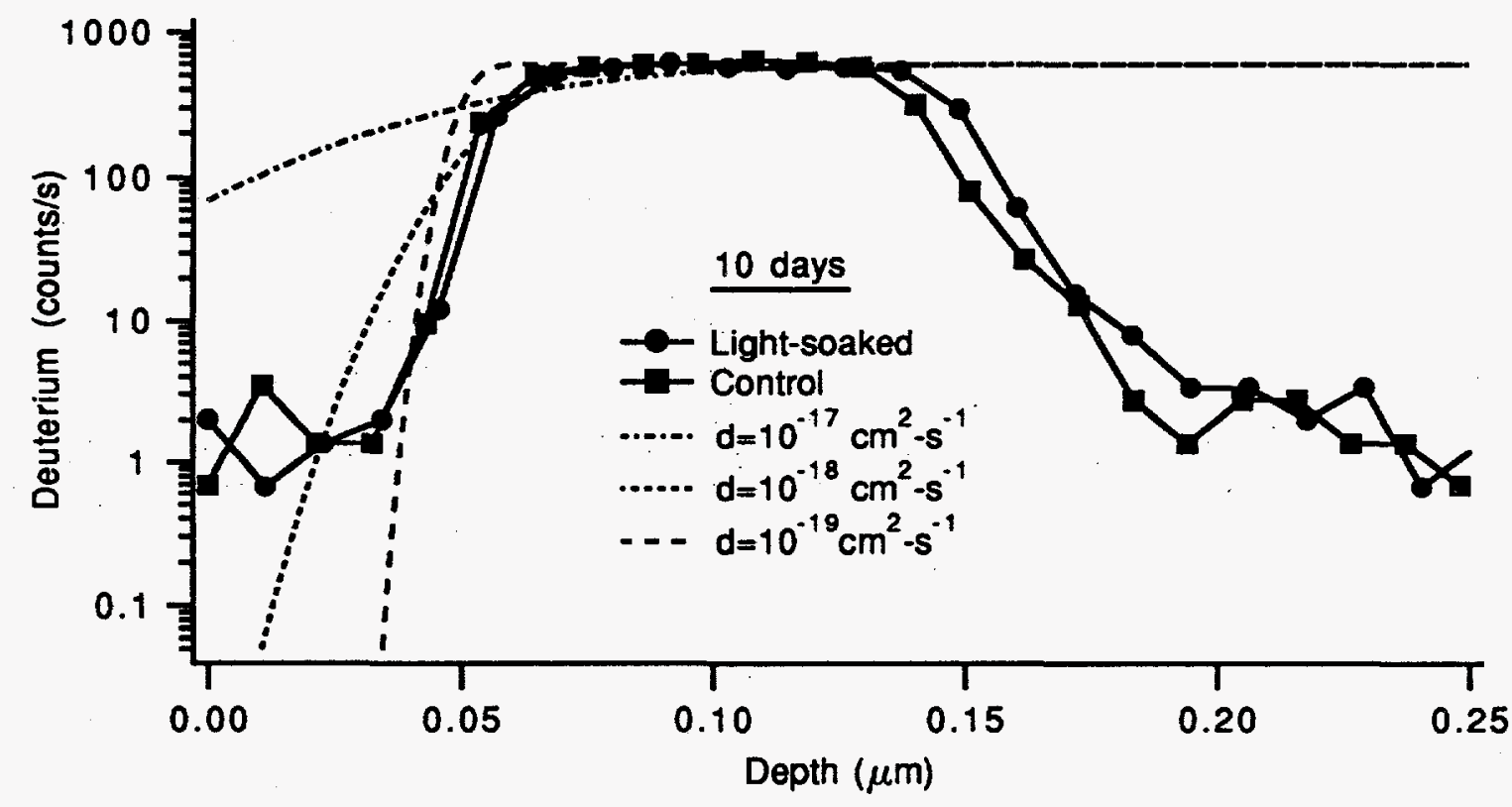

Figure 2-6. Deuterium SIMS results after ten days of room-femperature light-soaking (e). Dark control (a) and theoretical curves are also shown. 


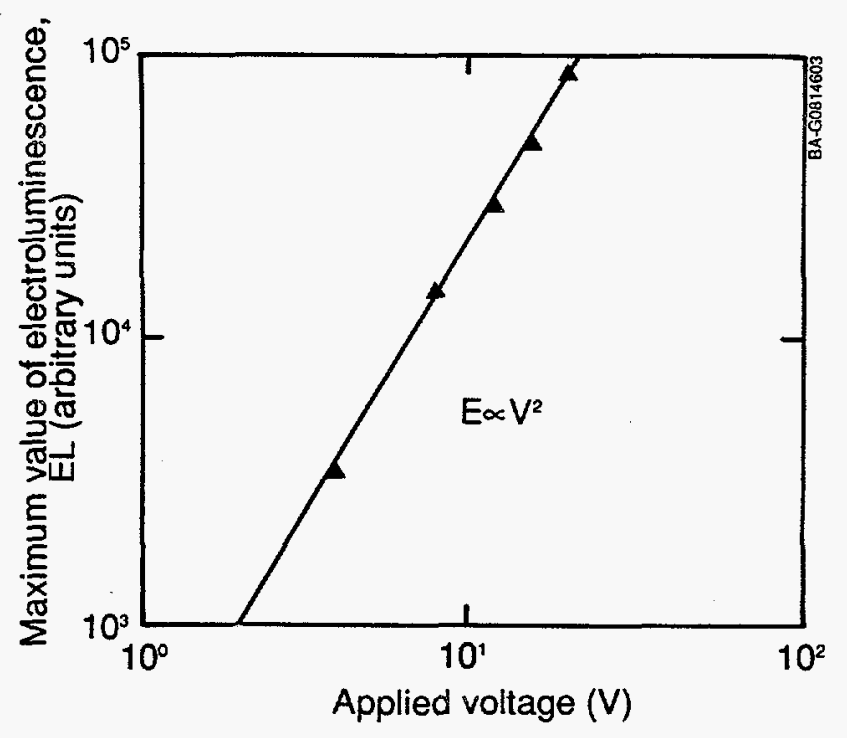

Figure 2-7. Maximum of electroluminescence versus voltage on log-log axes. Note that $E L \propto V^{2}$.

applied voltage is independent of temperature. This suggests that a tunneling step, rather than electron transport, controls the lifetime.

\section{Mobility-Lifetime Products in a-Si:H}

Ever since the first measurement (using the time-offlight charge-collection method) of the mobility-lifetime product, $(\mu \tau)_{T}$, in $\mathrm{a}-\mathrm{Si}: \mathrm{H}$, it has been a great puzzle why this quantity is about two orders of magnitude smaller (at standard measurement conditions) than the corresponding quantity determined from the steadystate photoconductivity, $(\mu \tau)_{s}$. Various explanations have been given for this difference. Some have attributed the difference to strong material anisotropy. However, the latest experimental findings show no such anisotropy in the transport parameters. Others speculated that the recombination centers change in the two types of measurements.

To resolve this dilemma, we analyze the basic differences between the two methods and derive the proper expression for $(\mu \tau)_{s}$. This is done because it appears that at least part of the confusion associated with the misinterpretation of the $\mu \tau$ products is a result of not applying the correct classical definitions of the characteristic times involved in describing the trapping and the recombination processes. Using these definitions, we demonstrate that holes in trap states play the role of sensitizing centers, making the recombination time much greater than the deep trapping time, and this is the reason that the experimental $(\mu \tau)_{S /}(\mu \tau)_{T}$ ratio is much larger than one. We obtain this ratio without invoking any additional states, other than the commonly accepted dangling bonds and band tail states.
Most of the confusion stems from not appreciating the correct definitions of the lifetimes. For a-Si:H, the electron recombination time contains both hole and electron trapping parameters and is written as

$$
\tau_{s}(R, n)=\tau_{n+}(n / p) \tau_{p},
$$

where $\tau_{n}$ and $\tau_{p}$ are the electron and hole trapping times and $n$ and $p$ are the free electron and hole densities, respectively. Using this definition, the ratio of $\mu \tau$ products is

$$
(\mu \tau)_{S} /(\mu \tau)_{T}=(N / n)_{T}\left(1_{+}(n / p) \tau_{p} / \tau_{n}\right),
$$

where $\mathrm{N}$ is the free plus trapped electron density. Because $N>n$, it is obvious that the ratio $(\mu \tau)_{S} /(\mu \tau)_{T}$ must be $>1$.

Using various experimental results, we show from the literature that the ratio of $(\mu \tau)_{\mathrm{S}} /(\mu \tau)_{\mathrm{T}}$ can be between 20 and $5 \times 10^{3}$.

\section{Diffusion Length Measurements by the Photocarrier Grating Technique}

Ambipolar diffusion length is an important parameter that characterizes the quality of a semiconductor material. The photocarrier grating technique, sometimes called the "steady-state photocarrier grating technique," is a simple and reliable method for determining the ambipolar diffusion length $\left(\mathrm{L}_{\mathrm{d}}\right)$. It is based on the creation of a small-amplitude photocarrier grating on a uniform photocarrier background.

The measurement apparatus is essentially an interferometer (see Figure 2-8). A beam splitter diverts the laser light onto two paths. The strong beam passes through a half-wave plate, which is used to rotate the plane of polarization. The weak beam passes through a chopper. A steady-state photocarrier grating is created by two interfering laser beams. The measurement is then repeated when the two beams are incoherent. The angle that the two beams make with respect to the sample normal determines the spatial frequency of the interference fringes. A voltage is applied to the sample through coplanar electrodes oriented such that the current flows perpendicular to the grating. The photocurrent caused by the chopped beam is measured using a lock-in amplifier when the beams are coherent and when they are incoherent. From a determination of the two photocurrents as a function of grating period, the diffusion length of the photocarriers can be obtained. It is convenient that the exact values for the current are not required.

We have measured ambipolar diffusion lengths ranging from about 500 to $2000 \AA$ with an accuracy of better than $10 \%$. 


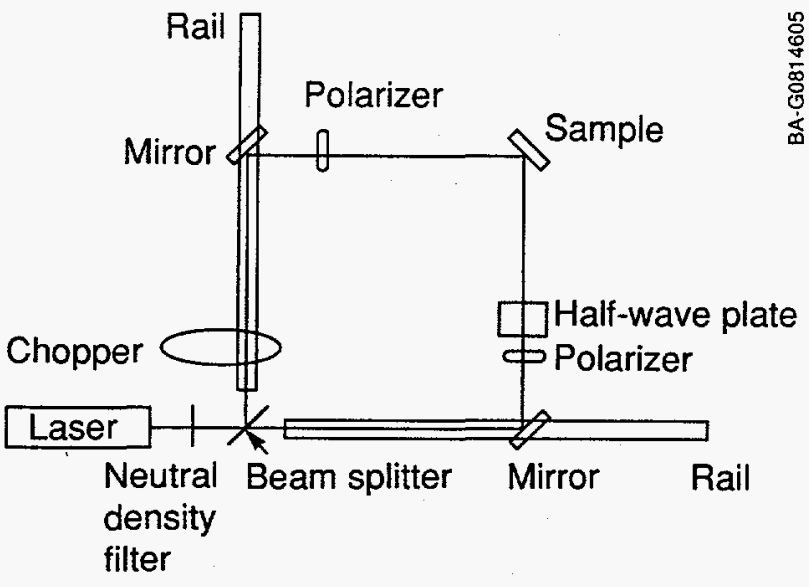

Figure 2-8. Layout of optical components for the photocarrier grating technique

\section{Publications and Presentations}

\section{Publications Included in Volume II}

A. H. Mahan, J. Carapella, B. P. Nelson, R. S. Crandall, and I. Balberg, "Deposition of Device Quality, Low $\mathrm{H}$ Content Amorphous Silicon," J. Appl. Phys. 69, 1991, pp. 6728-6730.

A. H. Mahan, D. L. Williamson, B. P. Nelson, and R. S. Crandall, "Characterizations of Microvoids in Device-Quality Hydrogenated Amorphous Silicon by Small-Angle X-Ray Scattering and Infrared Measurements," Phys. Reo. B40, 1989.

T. J. McMahon, "Defect Equilibration and Metastability in Low-Spin-Density Amorphous Hydrogenated Silicon," Solar Cells 30, 1991, pp. 235-243.

Y. S. Tsuo, Y. Xu, D. W. Baker, and S. K. Deb, "Etching Properties of Hydrogenated Amorphous Silicon," Materials Research Society Symposium Proceedings, 219, 1991, p. 805.

Y. S. Tsuo, Y. Xu, E. A. Ramsay, R. S. Crandall, S. J. Salamon, I. Balberg, B. P. Nelson, Y. Xiao, and C. Yan, "Methods of Improving Glow-DischargeDeposited a- $\mathrm{Si}_{1-x} \mathrm{Ge}_{\mathbf{x}}: \mathrm{H}, "$ Materials Research Society Symposium Proceedings, 219, 1991.

K. Wang, D. Han, M. Silver, and H. M. Branz, "Electroluminescence Studies of Recombination in Hydrogenated Amorphous Silicon p-i-n Devices," Solar Cells 30, 1991.

\section{Other Publications}

H. M. Branz, "Comment on 'Excitation-Energy Dependence of Optically Induced ESR in a-Si:H'," Phys. Rev. B41, 1990, pp. 7887-7890.

H. M. Branz and M. Silver, "Defect Thermodynamics, Inhomogeneity and the Density of Gap States in Hydrogenated Amorphous Silicon," in Amorphous Silicon Technology-1990, A. Madan, M. J. Thompson, P. C. Taylor, P. G. LeComber, and Y. Hamakawa, eds., Pittsburgh, Pennsylvania: Materials Research Society, 1990, pp. 261-272.

H. M. Branz and M. Silver, "Potential Fluctuations due to Inhomogeneity in Hydrogenated Amorphous Silicon and the Resulting Charged Dangling-Bond Defects," Phys. Rev. B42, 1990, pp. 7420-7428.

R. S. Crandall and H. M. Branz, "Band Bending due to Charged Dangling Bonds in Amorphous Silicon p-i-n Solar Cells," in Twenty First IEEE Photovoltaic Specialists Conference--1990, New York: Institute of Electrical and Electronics Engineers, 1990.

X. J. Deng, Y. S. Tsuo, and J. U. Trefny, "Ion-Beam Hydrogenation of Sputter-Deposited Amorphous Silicon and Amorphous Silicon-Germanium Alloys," Twenty First IEEE Photovoltaic Specialists Conference1990, New York: Institute of Electrical and Electronics Engineers, 1990.

R. Galloni, M. Ruth, A. Desalvo, and Y. S. Tsuo, "Low Energy Ion-Beam Posthydrogenation of Phosphorus Implanted Amorphous Silicon Films," Physica B Condensed Matter 170, 1991, pp. 273-276.

R. Galloni, Y. S. Tsuo, D. W. Baker, and F. Zignani, "Doping and Hydrogenation by Ion Implantation of Glow Discharge Deposited Amorphous Silicon Films," Appl. Phys. Lett. 56, 1990, p. 241.

D. Han, J. I. Pankove, Y. S. Tsuo, C. H. Qiu, and Y. Xu, "Improvement of a-Si $\mathrm{Si}_{1-x} \mathrm{C}_{\mathbf{x}}: \mathrm{H} / \mathrm{a}-\mathrm{Si}: \mathrm{H} \mathrm{p} / \mathrm{i}$ Interface by Hydrogen-Plasma Flushing Studied by Photoluminescence," Journal of Materials Research, in press.

S. Kar, J. I. Pankove, and Y. S. Tsuo, "Remote Plasma Hydrogenation of Ion Beam Amorphized Silicon," Appl. Phys Lett. 59, 1991, p. 718.

T. J. McMahon and R. S. Crandall, "Safe Hole Trap Conversion Properties and Microscopic Models," J. Non. Cryst. Solids 114, 1989, p. 615.

T. J. McMahon and R. S. Crandall, "Safe Hole Traps-A Source of Metastable Light-Induced Dangling Bonds in a-Si:H," Phil. Mag. 61, 1990, p. 425. 
Y. S. Tsuo and W. Luft, "Alternative Deposition Processes for Hydrogenated Amorphous Silicon and Related Alloys," a Featured Review Article in Applied Physics Communications 10, 1990, pp. 71-141.

Y. S. Tsuo, Y. Xu, and R. S. Crandall, "Hydrogen Plasma Reactive Flush for a-Si:H and a-SiGe:H Solar Cell Fabrication," Twenty First IEEE Photovoltaic Specialists Conference--1990, New York: Institute of Electrical and Electronics Engineers, 1990.

Y. Xiao, J. I. Pankove, Y. S. Tsuo, and R. S. Crandall, "Defect Band Electroluminescence in a-Si:H p-i-n Structure," submitted to the Journal of Materials Research.

\section{Presentations and Patents}

"Carrier-Induced Metastability in Hydrogenated Amorphous Silicon: Evidence of a Charge-Trapping Defect," presented at the Workshop on Defects, Hydrogen and Metastability in Crystalline and Amorphous Silicon, Golden, Colorado, October 1990.
A. H. Mahan, J. Carapella, and A. C. Gallagher, "Deposition of Device Quality, Low H Content Amorphous Silicon by the Hot Filament Technique," Patent Application (SERI IR \#90-49).

T. J. McMahon, "Thermal Equilibrium and Metastability in a-Si:H," presented at EPRI Smart IV, Palo Alto, California, January 1990.

Y. S. Tsuo and S. K. Deb, "Hydrogen Ion Microlithography," United States Patent \#4,960,675, October 2, 1990. 
Section 3

\section{Polycrystalline Thin Films}

\section{Investigators}

\author{
R. Noufi, Principal Scientist and Task Leader \\ D. S. Albin, Staff Scientist \\ J. Tuttle, Staff Scientist \\ M. Contreras, Associate Engineer \\ J. Dolan, Master Technician \\ J. Carapella, Master Technician \\ A. Duda, Student \\ A. Tennant, Student
}

\section{Objectives}

The task objective was to fabricate and investigate promising thin-film solar cell materials and devices to contribute to the goals of the DOE Photovoltaic Program. Specifically, the primary directives of this research were as follows: (1) fabricate, characterize, and modify $\mathrm{Cu}(\mathrm{In}, \mathrm{Ga}, \mathrm{Al}) \mathrm{Se}_{2}$ alloy thin films and devices by vacuum evaporation and selenization; (2) fabricate modified structures of these materials for device fabrication to increase open-circuit voltage $\left(\mathrm{V}_{\mathrm{oc}}\right)$ and short-circuit current density $\left(\mathrm{J}_{\mathrm{sc}}\right.$ ); (3) build a stateof-the-art process for fabricating $\mathrm{CuInSe}_{2}$ by selenization; (4) analyze, model, and microstructurally characterize the device structures; and (5) conduct a preliminary investigation of the rapid thermal processing of layered or composite $\mathrm{Cu} / \mathrm{In} / \mathrm{Se}$ to form large-grained CuInSe ${ }_{2}$

To achieve the task objectives, we concentrated on two closely related lines of study: (1) material fabrication and characterization, and (2) device fabrication, characterization, and modeling.

The common methodology in our approach was the multivariable matrix method. This approach involved defining a parameter space of processing variables for fabricating materials to be either characterized or used in a device application. The resulting film electrooptical and structural properties, or the device performance parameters, are related back to the initial choice of experimental variables. Preliminary conclusions were subsequently drawn on the initial parameter space, the parameter space was subsequently narrowed, and a new set of experiments was defined.

\section{Major Accomplishments}

\section{Selenization Process}

Selenization is the key process by which state-of-the-art $\mathrm{CuInSe}_{2}$, polycrystalline thin-film photovoltaic devices are fabricated. However, pertinent issues identified by industry remain to be investigated if increasing gains in efficiency and manufacturability are to be realized. These issues served as guidelines for our technical approach and were addressed by (1) identifying mechanisms related to interfacial adhesion,

(2) optimizing the starting $\mathrm{Cu} / \mathrm{In} / \mathrm{Ga}$ precursor regarding structure and compositional parameters, and (3) understanding the selenization process dynamics.

This study focussed within that region of process space conducive to fabricating high-efficiency, device-quality films.

In FY 1990, we concentrated on building a selenization process apparatus centered on a reaction chamber heated with infrared radiation from tungsten lamps. State-of-the-art safety mechanisms were incorporated to ensure safe handling of the poisonous $\mathrm{H}_{2} \mathrm{Se}$ gas and the efficient scrubbing of the latter to levels below the recommended threshold level value (TLV) level of 50 parts per billion. Figure 3-1 shows a schematic of this apparatus.

An important issue for the selenization process is to understand the phase behavior of the $\mathrm{Cu}$ and In precursors; this behavior dictates the resulting CuInSe ${ }_{2}$ film. The following is a summary of such a preliminary study.

We studied the phase behavior and microstructure of sequentially evaporated In-on-Cu layer stacks deposited on Mo-coated glass substrates (hereafter designated as In/Cu/Mo/glass structures). We determined that both equilibrium and non-equilibrium phases can exist, depending on processing. Indium evaporated onto copper, without intentional substrate heating and no subsequent annealing, resulted in the formation of the CuIn (JCPDS card \#35-1100) alloy phase and an unreported face-centered cubic (fcc) phase of undetermined composition. Auger spectrometry and $x$-ray diffraction (XRD) strongly suggested that this was a new $\mathrm{Cu}$-In alloy. Indium evaporated onto copper with substrate heating at $200^{\circ} \mathrm{C}$, followed by uncontrolled cooling to room temperature, strongly favored the 


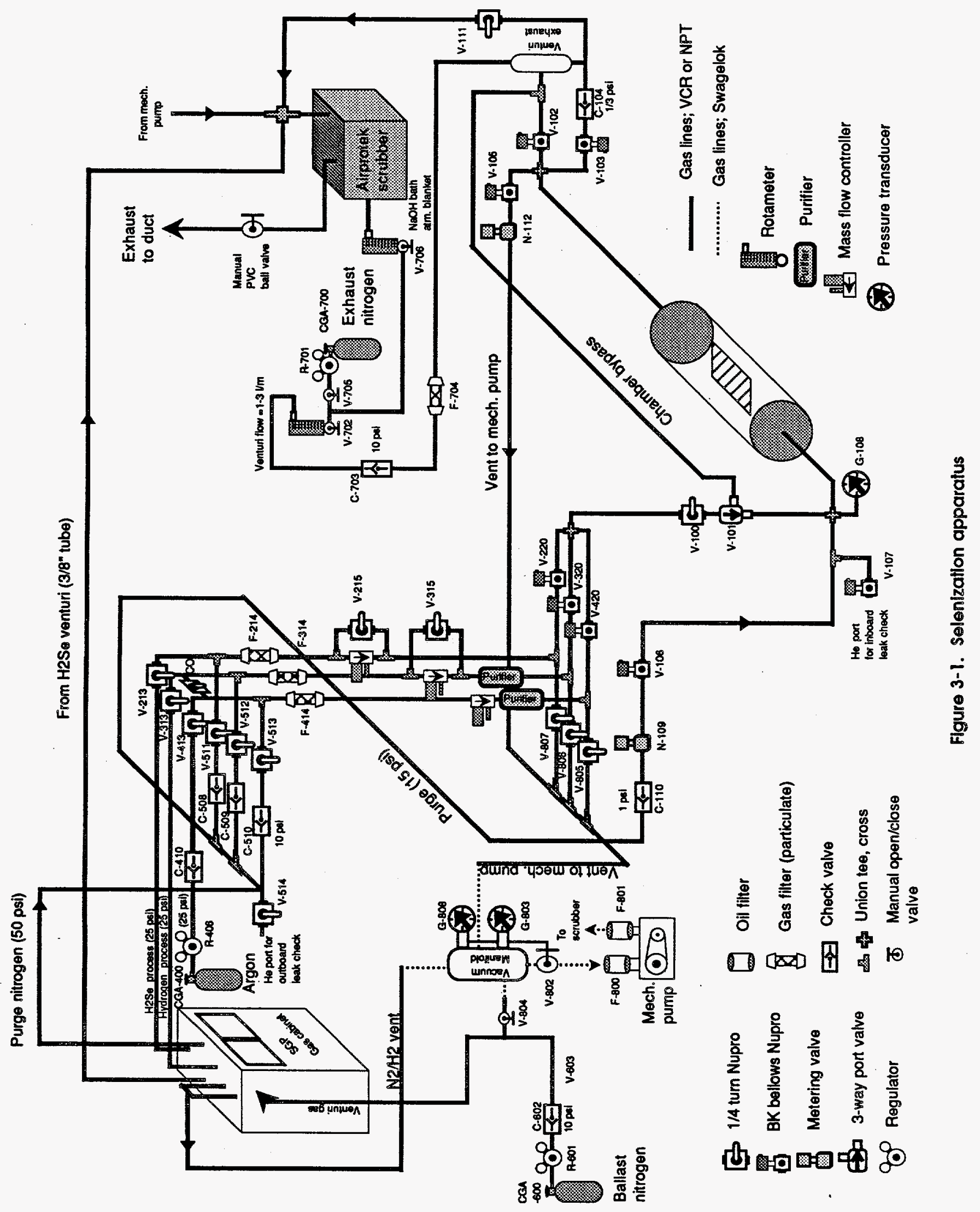




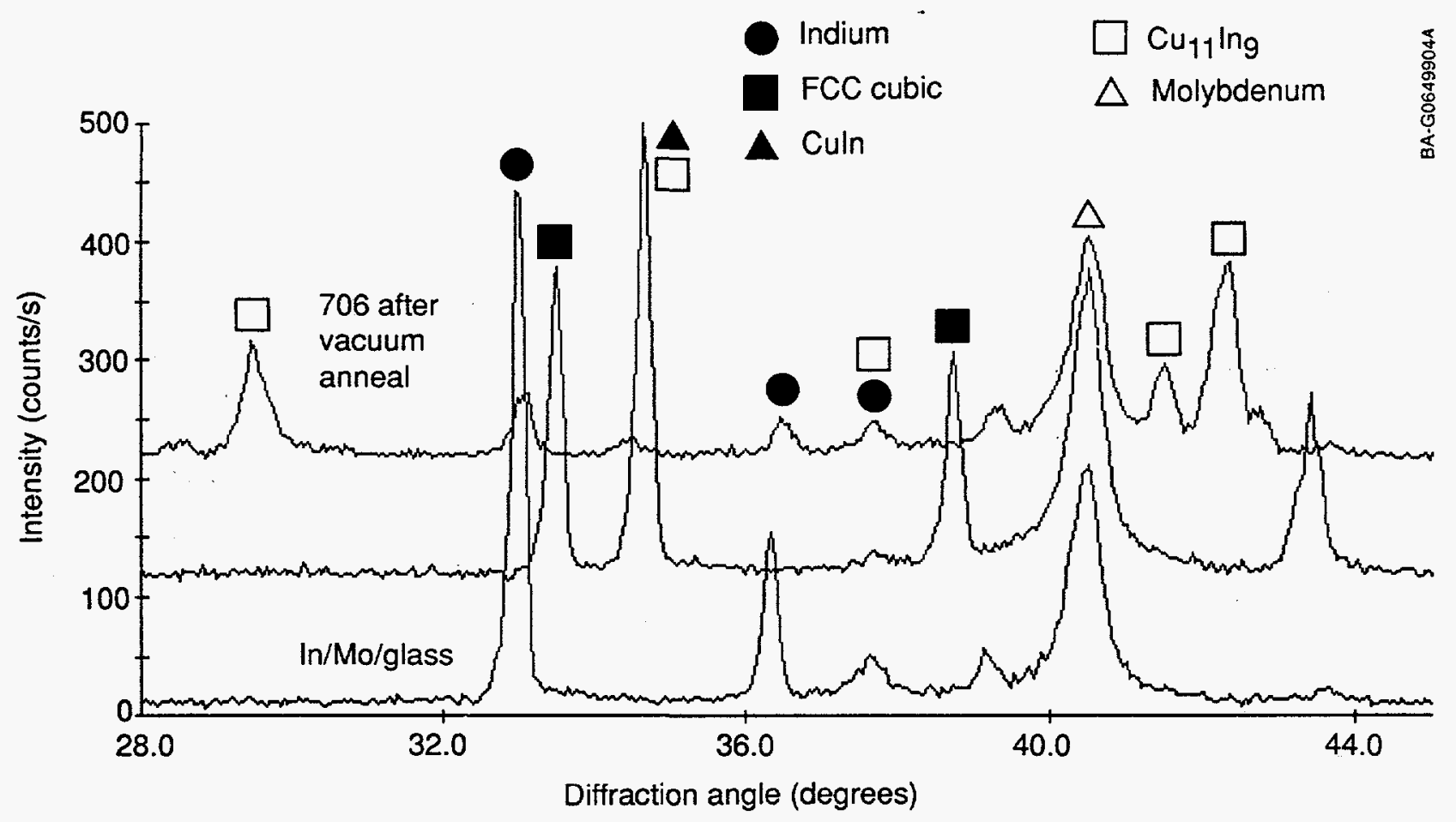

Figure 3-2. X-ray diffraction data showing the formation of indium and $\mathrm{Cu}_{11} \ln _{9}$ in sample 706 after vacuum annealing at $200^{\circ} \mathrm{C}$ for one hour. The bottom scan is of indium deposited on Mo/glass without copper.

formation of $\mathrm{Cu}_{11} \mathrm{In}_{9}$ while simultaneously reducing the concentration of both CuIn and the new fcc alloy phase as shown in Figure 3-2. Implications of these observations are discussed with regard to future selenization experiments in Albin et al. (1991a).

\section{Optical and Microstructural Characteristics of $\mathrm{Cu}(\mathrm{In}, \mathrm{Ga}) \mathrm{Se}_{2}$ Polycrystalline Thin Films}

The optical and microstructural properties of polycrystalline $\mathrm{CuIn}_{1-y} \mathrm{Ga}_{y} \mathrm{Se}_{2}$ thin films deposited by coevaporation were reported within the boundaries of an orthogonal experimental design investigating the effects of $\mathrm{Cu}$ flux, $\mathrm{Ga} /(\mathrm{Ga}+\mathrm{In})$ composition, Se rate, substrate temperature, and substrate type. The optical band gaps (Figure 3-3) for near-stoichiometric $\mathrm{CuIn}_{1-y} \mathrm{Ga}_{\mathrm{y}} \mathrm{Se}_{2}$ were smaller and exhibited a bowing behavior that followed the relationship $\mathrm{E}_{\mathrm{g}}=1.011+$ $0.664 y+0.249 y(y-1)$. In comparison, Cu-poor films exhibit a linear variation with zero bowing, given by $E_{g}=1.0032+0.71369 y$. The increase in $E_{g}$ with decreasing $\mathrm{Cu}$ may result in part from lattice shrinkage as measured by XRD.

Optical absorption below the band edge appeared to depend on both $\mathrm{Cu}$ and $\mathrm{Ga}$ content. Absorption coefficients of $\alpha \geq 10^{3} \mathrm{~cm}^{-1}$ within this region were indicative of Cu-rich films. Simultaneously, absorption $\leq 10^{3} \mathrm{~cm}^{-1}$ may have been dictated more by surface morphology and possible phase separation in films containing $\geq 50 \%$
Ga. The magnitude of $\alpha$ varied from $\cong 2 \times 10^{4}$ near the band edge up to $10^{5} \mathrm{~cm}^{-1}$ at $1 \mathrm{eV}$ above the edge for near-stoichiometric films with absorption in Cu-poor films being slightly less. The details of this study are given in Albin et al. (1990).

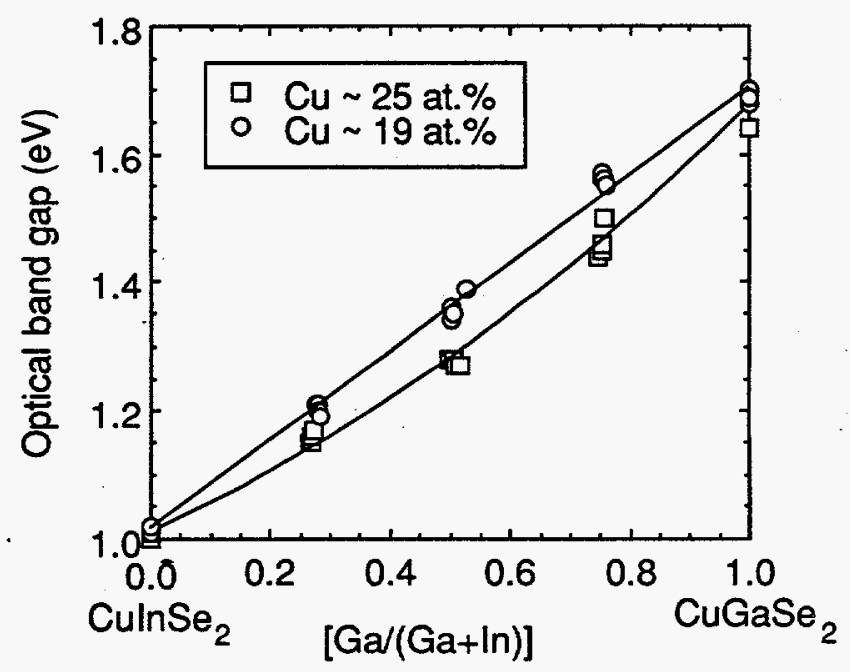

Figure 3-3. Optical band gap as a function of gallium and copper content 
Microstructural Characterization of Polycrystalline $\mathrm{CuInSe}_{2}$ Thin Films: Ramifications on Device Performance

The microstructure and morphology of polycrystalline thin-film CuInSe ${ }_{2}$ have been studied extensively in the compositional range of $17-32$ at. $\% \mathrm{Cu}$. The grain size scaled with substrate temperature and $\mathrm{Cu}$ content, and in variable ways with substrate type; grains ranged in size from 0.1 to $5.0 \mu \mathrm{m}$. The morphology of Cu-rich films additionally appeared to depend on the resident nucleation and growth of the $\mathrm{Cu}_{2-\delta}$ Se binary compound. A microstructural model of polycrystalline thin-film CulnSe ${ }_{2}$ is presented in Figure 3-4 and suggests that the inter-granular microstructure is dominated by the compositional and substrate

Cu-poor

(a)

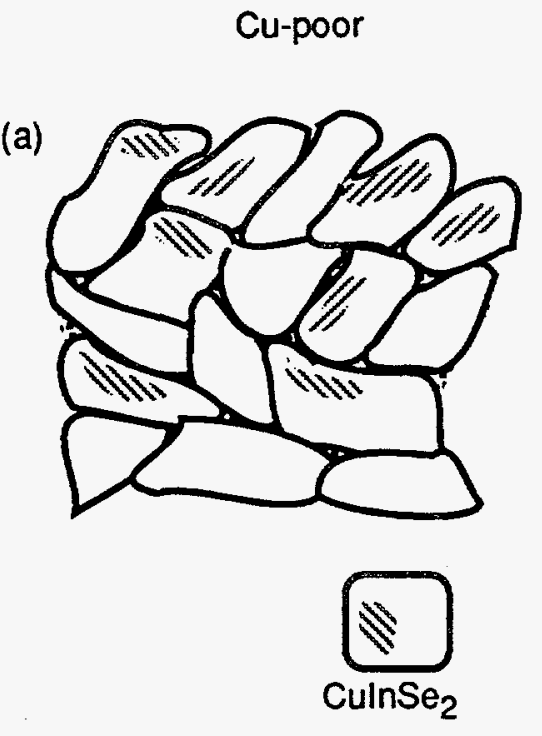

(b)

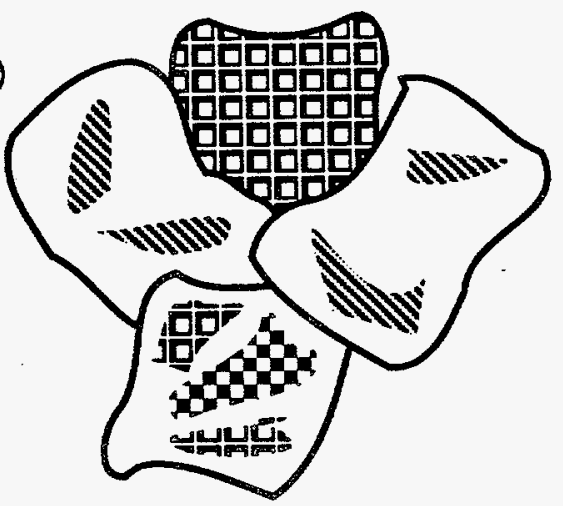

temperature dependence of $\mathrm{Cu}_{2-\delta} \mathrm{Se}$ precipitation at grain boundaries and free surfaces. The intra-granular microstructure of the near-stoichiometric grain is a phase-separated mixture of ordered chalcopyrite and disordered sphalerite, with $\mathrm{Cu}_{\mathrm{x}} \mathrm{Se}(\mathrm{x}=0.5,1.0,1.5,2.0)$ minority phase inclusions. Off-stoichiometric, $\mathrm{Cu}$-poor film compositions additionally contain isolated grains of the chalcopyrite-variant ordered-vacancy compound $\mathrm{CuIn}_{2} \mathrm{Se}_{3.5}$. The potential ramifications of the microstructure on the device performance included a reduced photo-active volume, carrier transport across phase boundaries, and the dependence of transport parameters on the crystallite size. Refer to the following articles for details: Tuttle et al. (1990a), Tuttle et al. (1990b), and Tuttle et al. (1991).
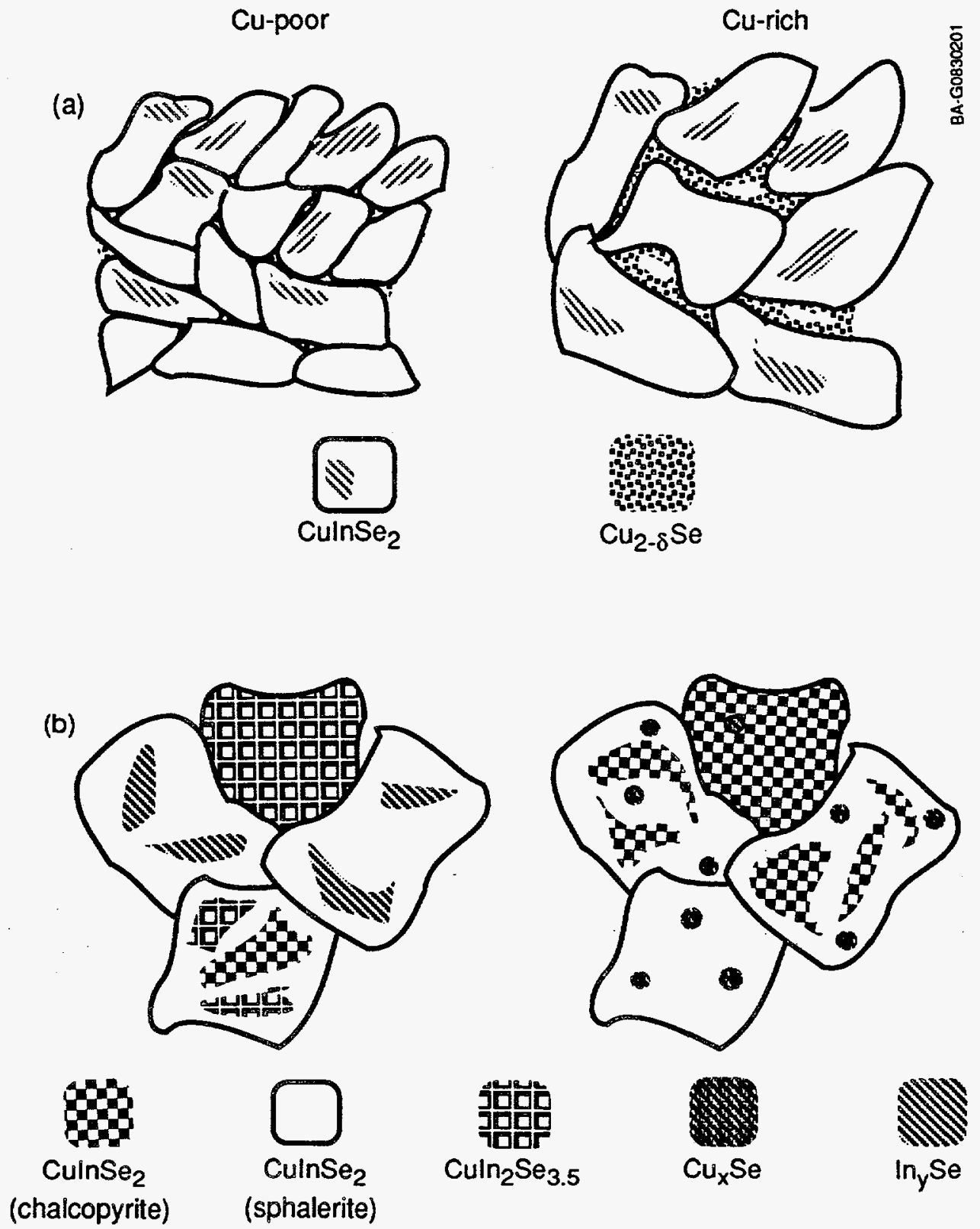

Figure 3-4. Microstructural model of polycrystalline thin-film CulnSe $e_{2}$. The images shown are intergranular (a) and intragranular (b) models. 


\section{Rapid Thermal Processing of CuInSe ${ }_{2}$ Thin Films}

The rapid thermal processing technique can be used as a synthesis tool to fabricate thin films from precursors (e.g., CuInSe ${ }_{2}$ from layered or homogenous $\mathrm{Cu} / \mathrm{In} / \mathrm{Se}$ ) and diffused but sharp thin-film junctions between layers; it can also enhance grain growth in polycrystalline thin films. Here, we present exploratory work to form $\mathrm{CuInSe} \mathrm{S}_{2}$ thin films and enhance the grain growth of polycrystalline CuInSe ${ }_{2}$.

The formation of polycrystalline thin-film CuInSe 2 has been achieved by the rapid thermal processing of vacuum co-deposited $\mathrm{Cu}$, In, and Se. We fabricated and characterized films in three composition regions: $\mathrm{Cu}$-poor $(-20$ at. $\% \mathrm{Cu})$, stoichiometric (25 at. \% Cu) and $\mathrm{Cu}$-rich $(-28$ at. $\% \mathrm{Cu})$. We present characterization results, including XRD analysis, electron probe for microanalysis, scanning electron microscopy, and optical reflection and transmission measurements. Results show that nearly single-phase material was formed from co-deposited precursors with a postdeposition annealing time of less than two minutes (see Figure 3-5). The films have smooth morphologies amenable for photovoltaic device fabrication, optical absorption coefficients in the high $10^{4} \mathrm{~cm}^{-1}$ range, and an optical band gap of $1.0 \mathrm{eV}$.

Rapid thermal processing of precursor small-grained $(\leq 1 \mu \mathrm{m}) \mathrm{CuInSe}_{2}$ thin films can result in enhanced grain growth on the order of $100 \mu \mathrm{m}$ under certain processing conditions. Crystal growth was accompanied by large increases $(x 10)$ in the XRD intensity of the (112) peak, indicating near-perfect crystal growth in the [221] direction. Single-crystal quality was verified by selected-area electron channeling. However, this effect currently occurs in conjunction with excessive void and pinhole formation between single-crystal platelets. These voids are often decorated with relatively Se-deficient phases. Details on this work can be found in Mooney et al. (1991) and Albin et al. (1991b).

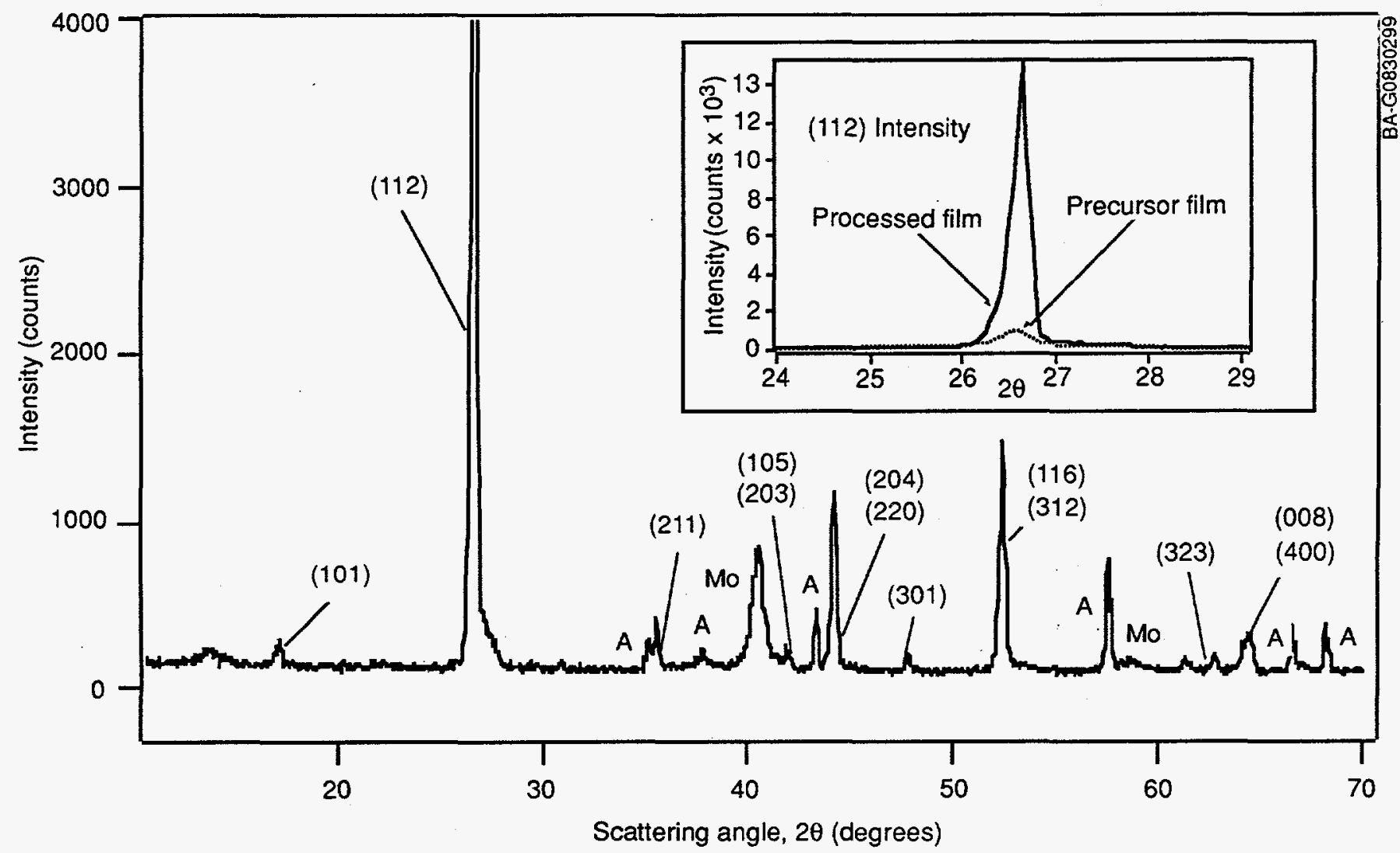

Figure 3-5. XRD pattern of a co-deposited CulnSe ${ }_{2}$ thin film processed by rapid thermal processing. The inset is a comparison of the (112) peak of the same film and its precursor, demonstrating significant recrystallization. "A" designates the alumina peaks, and "Mo" designates the molybdenum peaks. 


\section{Publications and References}

\section{Publications Included in Volume II}

D. S. Albin, G. D. Mooney, J. J. Carapella, A. Duda, J. R. Tuttle, R. Matson, and R. Noufi, "The Phase Behavior of Evaporated Copper and Indium Precursors for Selenization," Solar Cells 30, 1991a, p. 41.

D. S. Albin, J. R. Tuttle, G. D. Mooney, J. J. Carapella, A. Duda, A. Mason, and R. Noufi, "A Study on the Optical and Microstructural Characteristics of Quaternary $\mathrm{Cu}(\mathrm{In}, \mathrm{Ga}) \mathrm{Se}_{2}$ Polycrystalline Thin Films," Twenty First IEEE Photovoltaic Specialists Conference1990, New York: Institute of Electrical and Electronics Engineers, 1990, p. 562.

G. D. Mooney, A. M. Hermann, J. R. Tuttle, D. S. Albin, and R. Noufi, "The Formation of CuInSe Thin Films by Rapid Thermal Processing," Solar Cells 30,1991, p. 69 .

J. R. Tuttle, D. S. Albin, and R. Noufi, "Thoughts on the Microstructure of Polycrystalline Thin Film CuInSe ${ }_{2}$ and Its Impact on Material and Device Performance," Solar Cells 30, 1991, p. 21.

J. R. Tuttle, D. S. Albin, J. P. Goral, and R. Noufi, "Secondary and Polymorphic Phase Behavior of Thin Film CuInSe: Ramifications on the Device Performance," Twenty First IEEE Photoooltaic Specialists Conference-1990, New York: Institute of Electrical and Electronics Engineers, 1990a, p. 748.

\section{Other Publications}

D. S. Albin, G. D. Mooney, A. Duda, J. R. Tuttle, R. Matson, and R. Noufi, "Enhanced Grain Growth in
Polycrystalline CuInSe, Using Rapid Thermal Processing," Solar Cells 30, 1991b, p. 47.

I. Balberg, D. Albin, and R. Noufi, "Towards Optimization and Understanding of the Photoelectronic Properties in CuGaSe ${ }_{2}$ " Appl. Phys. Lett. 58, 2, 1991.

D. Cahen and R. Noufi, "Surface Passivation of Polycrystalline, Chalcogenide Based Photovoltaic Cells," Solar Cells 30, 1991, p. 53.

J. P. Goral, M. M. Al-Jassim, D. Albin, J. R. Tuttle, and R. Noufi, "TEM Identification of Secondary Phases in Non-Stoichiometric Polycrystalline CuInSe ${ }_{2}$ Thin Films," Proceedings of the 12th International Congress for Electron Microscopy, San Francisco, California: San Francisco Press, Inc., 1990, p. 604.

R. Noufi and D. Cahen, "Free Energies and Enthalpies of Possible Gas Phase and Surface Reactions for Preparation of CuInSe $e_{2}$ " J. Phys. and Chem. of Solids, in press.

J. R. Tuttle, D. S. Albin, J. Carapella, and R. Noufi, "Microstructural Characterization of Polycrystalline Thin-Film CuInSe $e_{2}$ A Promising Yet Complex Material for PV Applications," Proceedings of the 25th Intersociety Energy Conversion Engineering Conference, Reno, Nevada, New York: American Institute of Chemical Engineers, 1990b, p. 31.

J. R. Tuttle, "An Optical and Microstructural Characterization Study and Microstructural Model of CoEvaporated Polycrystalline Thin Film CuInSe ${ }_{2}$ for Photovoltaic Applications," Ph.D. Dissertation, May 1990. 


\section{Section 4}

\section{III-V High-Efficiency Photovoltaic Cells}

\section{Investigators}

\author{
J. M. Olson, Principal Scientist \\ K. Bertness, Staff Scientist \\ D. Friedman, Staff Scientist \\ A. Kibbler, Staff Scientist \\ S. Kurtz, Staff Scientist \\ E. Beck, Technician \\ P. Faine, Visiting Scientist
}

\section{Objectives}

The lattice-matched $\mathrm{GaInP}_{2} / \mathrm{GaAs}$ cascade solar cell has a high potential for achieving one-sun and multisun efficiencies greater than $30 \%$ and $34 \%$, respectively. The main task in this research is to continue developing the $\mathrm{GaInP}_{2} / \mathrm{GaAs}$ cascade structure. The longterm objectives of this task are to (1) conduct research leading to an understanding of the problems inherent in fabricating such high-efficiency cascade photovoltaic cells, and (2) conceive and develop new approaches and ideas to solve these problems. Specific research areas during FY 1990 included the following:

1. Device modeling, fabrication, and characterization

2. Materials characterization using photocurrent spectroscopy, photoluminescence, photoreflectance, and Hall analysis

3. Defect analysis and dislocation studies using high-resolution $x$-ray double-crystal diffraction and transmission electron microscopy (TEM)

4. Basic crystal growth studies of the mechanisms of defect generation and propagation, and the control of impurity and point defect concentrations.

\section{Major Accomplishments}

\section{Tandem Cell Modeling}

The efficiencies of solar cells depend on the conditions under which the efficiency is measured. We completed a theoretical study showing the sensitivities of various one-, two-, and three-junction III-V solar cell efficiencies to variations in spectra and temperature. When choosing the optimal cell, the designers must carefully weigh the expected variations in temperature and spectra. This study showed that high-band-gap cells are sensitive to variations in air mass and turbidity (haziness), while low-band-gap cells are sensitive to cell temperature and atmospheric water-vapor fluctuations. The penalty paid for parallel connection in a voltage-matched configuration is negligible for the high-band-gap cell. However, a significant penalty can occur for voltage-matched, lowband-gap cells if high temperatures are common. In contrast, the penalty paid for series connection in a current-matched configuration is negligible when temperature varations are considered, but the penalty is important for spectral variations, especially for the high-band-gap cells. For a high-band-gap, currentmatched cell compared to a similar four-terminal cell, there is a loss of $1.5 \%$ in absolute efficiency over a year's time because of air-mass fluctuations at $40^{\circ}$ latitude. Series connection of low-band-gap cells is much less of a problem.

\section{The Effect of Growth Rate on the Band Gap of GaInP $_{2}$}

The band gap of $\mathrm{Ga}_{0.5} \mathrm{In}_{0.5} \mathrm{P}$ is known to vary depending on the growth conditions because of variations in the arrangement of the gallium and indium atoms on the group III sublattice. A study of the dependence of band gap on growth rate and growth temperature showed that the dependence is quite complex (see Figure 4-1). At very high growth rates, the residence time of gallium and indium atoms on the surface ( $t)$ is less than the surface relaxation time to the ordered surface state $(\theta)$, yielding a disordered alloy with a high band gap. As the growth rate is decreased, $t$ increases relative to $\theta$ and the band gap (order) decreases (increases). For very low growth rates and low growth temperatures, the final state of the bulk alloy is determined by the rates of interdiffusion within a subsurface transition layer relative to the residence time within this layer. If the residence time in the transition layer is comparable to the relaxation time to the disordered state, then the band gap (order) increases (decreases) with decreasing growth rate. Activation energies for the surface and transition layer relaxation processes are consistent with published. activation energies in similar systems. 


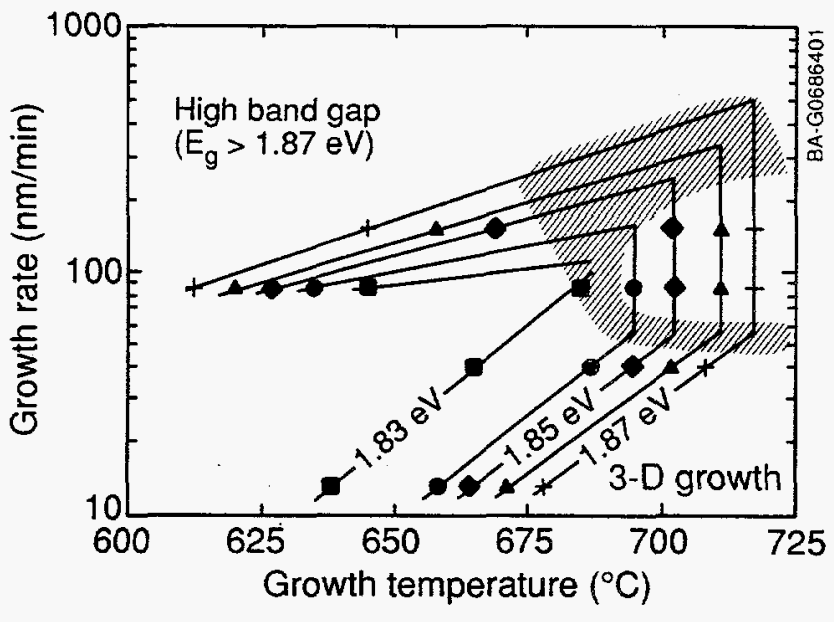

Figure 4-1. Iso-band-gap contour plot showing the variation of $G_{0.5} \ln _{0.5} P$ band gap with growth rate and growth temperature. The exact locations of the contours are not known in the hatched regions.

The Photoluminescence of $\mathrm{GaInP}_{2}$ and its Dependence on Excitation Intensity

We know that the degree of ordering and the band-gap energy of $\mathrm{GaInP}_{2}$ are functions of the growth conditions. In 1990, in collaboration with DeLong and Taylor at the University of Utah, we probed the band structure of $\mathrm{GaInP}_{2}$ using various $\mathrm{PL}$ techniques. In most high-purity III-V binary and ternary semiconductors, the PL spectrum does not shift in wavelength with excitation intensity by more than a fraction of a meV per decade of change in the excitation intensity. In $\mathrm{GaInP}_{2}$, we find a blue shift with increasing excitation intensity, the magnitude of which depends on growth conditions and substrate orientation. For (100) misoriented $2^{\circ}$ toward (110), the blue shift is maximum ( $12 \mathrm{meV} /$ decade) for layers that were grown at $650^{\circ} \mathrm{C}$ and exhibit the lowest band gap. For substrates misoriented toward $\{111\}$, the shift rate decreases monotonically from about $5 \mathrm{meV} /$ decade at a growth temperature of $600^{\circ} \mathrm{C}$ to less than $1 \mathrm{meV} /$ decade $750^{\circ} \mathrm{C}$. From previous results, it appears that the rate of shift is not directly related to the extent of ordering or band gap. We argue that the shift is caused by potential fluctuations and postulate that these fluctuations are a natural consequence of imperfect ordering, yielding a structure consisting of ordered domains of specific sizes distributed within a disordered matrix.

\section{Carbon Doping of InP, GaAs, and Related Alloys}

To solve systematic problems involving zinc doping in various cell structures, we tested pure carbon tetrachloride as a p-type dopant. We investigated the effect of growth temperature, V/III ratio, and $\mathrm{CCl}_{4}$ flux on the hole concentration in GaAs, InP, $\mathrm{Ga}_{0.5} \operatorname{In}_{0.5} \mathrm{P}$, and $\mathrm{Ga}_{0.5} \mathrm{In}_{0.5} \mathrm{As}$. We found $\mathrm{CCl}_{4}$ to be an excellent carbondoping source for metal-organic chemical vapor deposition (MOCVD)-grown GaAs, but an etchant, rather than a doping source, for InP. In the case of $\mathrm{Ga}_{0.5} \mathrm{In}_{0.5} \mathrm{P}$, etching was manifested by a change in the alloy's solid composition, while the composition of $\mathrm{Ga}_{0.5} \mathrm{In}_{0.5} \mathrm{As}$ was not significantly changed for comparable $\mathrm{CCl}_{4}$ flows. For $\mathrm{GaAs}$, the doping efficiency of $\mathrm{CCl}_{4}$ decreased sharply with growth temperature and was inversely proportional to the V/III ratio. The hole mobilities for carbon-doped GaAs were as high or higher than those for zinc-doped GaAs. Compensation was not a problem, even at hole concentrations exceeding $10^{19} \mathrm{~cm}^{-3}$. However, the electrical quality of carbon-doped $\mathrm{Ga}_{0.5} \mathrm{In}_{0.5} \mathrm{P}$ films was significantly lower than that of zinc-doped $\mathrm{Ga}_{0.5} \mathrm{In}_{0.5} \mathrm{P}$, and hole concentrations could not be increased above $10^{17} \mathrm{~cm}^{-3}$. Controlling the solid composition for $\mathrm{Ga}_{0.5} \mathrm{In}_{0.5} \mathrm{P}$ was increasingly difficult with increased $\mathrm{CCl}_{4}$ flux. The carrier concentration of InP films was unaffected by the input of $\mathrm{CCl}_{4}$ for the fluxes we investigated.

\section{Hall Mobility Studies of Ordering in GaInP ${ }_{2}$}

Deviations from random cation site disorder in pseudobinary semiconductor alloys are expected to contribute a distinctive curvature to the temperature dependence of the Hall mobility at high temperatures [Bhattacharya and $\mathrm{Ku}, 1985$ ]. To obtain an estimate of the ordering cluster size in GaInP, we measured the temperature dependence of the Hall mobility of GaInP samples grown under conditions known to produce either high or low ordering. Typical mobility curves for relatively ordered GaInP (growth temperature $\left[\mathrm{T}_{\mathrm{g}}\right]=670^{\circ} \mathrm{C}$ ) and relatively ordered GaInP $\left(\mathrm{T}_{\mathrm{g}}=600^{\circ} \mathrm{C}\right.$ ) are shown in Figure 4-2. We do not observe the characteristic sharp upward curvature in the mobility observed by Bhattacharya and $\mathrm{Ku}$ (1985) for related III-V alloys and ascribed by them to alloy cluster effects. We are presently extending our data to higher temperatures. We found that the substrate must be removed or it will induce artifactual behavior in the mobility data (resembling that observed by Bhattacharya and Ku [1985]).

\section{Construction of the New Organometallic Vapor Phase Epitaxy Growth System}

During FY 1990, we brought a new organometallic vapor phase epitaxy (OMVPE) reactor on line. We will use this system to grow $\mathrm{GaInP}_{2}$ and related highefficiency solar cell materials using germanium wafers as substrates for $\mathrm{GaAs}$ and $\mathrm{GaInP}_{2}$ layers. The gashandling hardware, controlling electronics and pneumatics, and computer software were all designed and constructed in house. The reactor executed its first run without incident on September 28, 1990. 


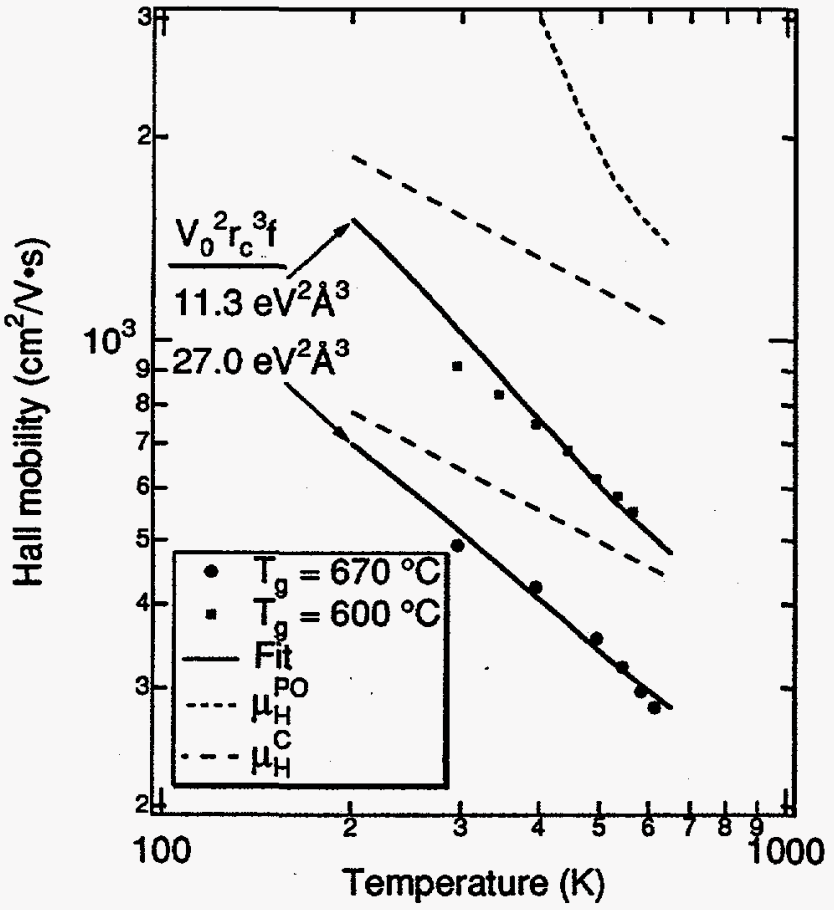

Figure 4-2. The measured Hall mobility $\left(\mu_{H}\right)$ tor partially ordered $\pi_{g}=670^{\circ} \mathrm{C}$ ) and disordered $\pi_{g}=$ $\left.600^{\circ} \mathrm{C}\right) 6 a_{0.5} \ln _{0.5} \mathrm{P}$. The fit to the data includes contributions from the polar optical mobility $\left(\mu_{H}^{\mathrm{PO}}\right), a$ cluster scattering ferm ( $\mu_{H}$, and an acoustic detormation potential term (not shown).

The design of the reactor differs from those of previous ones in three ways: (1) the reactor meets or exceeds all NREL safety requirements, (2) the redesigned inject system minimizes memory effects during growth, and (3) the control software is substantially enhanced over previous versions. The primary safety improvement is a high-efficiency particle filter absolute (HEPA) filtering system to remove arsenic oxides and other particles from the reactor effluent. This system is performing extremely well; we will probably add it to other NREL growth systems that currently allow small quantities of particulate waste to go through duct work and into the outside air. Another safety improvement consists of extending automated shutdown to a wider variety of potentially dangerous circumstances, such as a lack of ventilation, hydrogen purifier failure, inadequate pneumatic pressure to operate valves, a toxic gas monitor "high level" alarm, and reactor overpressure. The growth system also incorporates high-pressure-tolerant valves and excess flow shutoff devices that have recently become available. The second innovation in the growth system, the redesigned inject fitting, has produced unexpected compositional non-uniformities in $\mathrm{GaIn} \mathrm{P}_{2}$ epitaxial layers grown in the reactor. We have since worked to modify the inject system to correct this problem and have developed a better understanding of the gas flow dynamics in the reactor. Finally, the new reactor software allows the computer to control routine tasks that the operator or an auxiliary computer performed in older growth systems. The software has a much more user-friendly interface, and it includes calculations based on OMVPE growth theory and calibrations to allow more rapid translation of materials parameters into reactor gas flows and valve states. This improves the efficiency and reproducibility of reactor operation.

\section{Publications and Presentations}

\section{Publications Included in Volume II}

M. C. DeLong, P. C. Taylor, and J. M. Olson, "Excitation Intensity Dependence of Photoluminescence in $\mathrm{Ga}_{0.52} \mathrm{In}_{0.48} \mathrm{P}, "$ Appl. Phys. Lett. 57, 1990, p. 620.

M. C. DeLong, P. C. Taylor, and J. M. Olson, "Growth Temperature and Substrate Orientation Dependences of Moving Emission and Ordering in $\mathrm{Ga}_{0.52} \mathrm{In}_{0.48} \mathrm{P}$," J. Vac. Sci. Technol. B8, 1990, p. 948.

P. Faine, Sarah R. Kurtz, C. Riordan, and J. M. Olson, "The Influence of Spectral Solar Irradiance Variations on the Performance of Selected Single-Junction and Multijunction Solar Cells," Solar Cells 31, 1991, pp. 259.

A. Kibbler, Sarah R. Kurtz, and J. M. Olson, "Carbon Doping of MOCVD-Grown GaAs, InP, and Related Ternaries Using $\mathrm{CCl}_{4}, "$ J. Cryst. Growth 109, 1991, p. 258.

Sarah R. Kurtz, P. Faine, and J. M. Olson, "Modeling of Two-Junction, Series-Connected Tandem Solar Cells Using Top-Cell Thickness as An Adjustable Parameter," J. Appl. Phys. 68, 1990, p. 1890.

Sarah R. Kurtz, J. M. Olson, and A. Kibbler, "Effect of Growth Rate on the Band Gap of $\mathrm{Ga}_{0.5} \mathrm{In}_{0.5} \mathrm{P}$," Appl. Phys. Lett. 57, 1990, p. 1922.

Sarah R. Kurtz, J. M. Olson, and A. Kibbler, "High Efficiency GaAs Solar Cells Using GaInP ${ }_{2}$ Window Layers," Twenty First IEEE Photovoltaic Specialists Conference-1990, New York: Institute of Electrical and Electronics Engineers, 1990, p. 138.

Sarah R. Kurtz, J. M. Olson, J. P. Goral, A. Kibbler, and E. Beck, "The Effect of Selenium Doping on the Optical and Structural Properties of $\mathrm{Ga}_{0.5} \mathrm{In}_{0.5} \mathrm{P}, "$ J. Elect. Mater. 19,1990, p. 825.

Sarah R. Kurtz, J. M. Olson, and P. Faine, "The Difference Between Standard and Average Efficiencies of Multijunction Compared with Single-Junction Concentrator Cells," Solar Cells 30, 1991, p. 501. 
J. M. Olson, Sarah R. Kurtz, A. E. Kibbler, and P. Faine, "Recent Advances in High Efficiency $\mathrm{GaIn}_{2} / \mathrm{GaAs}$ Tandem Solar Cells," Twenty First IEEE Photovoltaic Specialists Conference-1990, New York: Institute of Electrical and Electronics Engineers, 1990.

\section{Other Publications}

K. A. Bertness, J. I. Cubbage, and J. G. Werthen, "Growth Rate and Doping Uniformity in An Atmospheric-Pressure Multiwafer OMVPE Reactor," J. Cryst. Growth 109, 1991, p. 234.

K. A. Bertness, M. Ladle Ristow, M. Klausmeier-Brown, M. Grounner, M. S. Kuryla, and J. G. Werthen, "16\%-Efficient GaAs Solar Cell After $10^{15} \mathrm{~cm}^{-2}, 1-\mathrm{MeV}$ Radiation," Twenty First IEEE Photovoltaic Specialists Conference--1990, New York: Institute of Electrical and Electronics Engineers, 1990, p. 1231.

P. K. Bhattacharya and J. W. Ku, "Effect of Alloy Clustering on the High Temperature Electron Mobility in $\mathrm{In}_{1-x} \mathrm{Ga}_{x} \mathrm{As}_{\mathrm{y}} \mathrm{P}_{1-\mathrm{y}}, "$ J. Appl. Phys. 58, 1985, p. 1410.

P. J. Faine, Sarah R. Kurtz, and J. M. Olson, "Modeling of Two-Junction, Series-Connected Tandem Solar Cells Using Top-Cell and Coating Thicknesses as Adjustable Parameters," Twenty First IEEE Photovoltaic Specialists Conference-1990, New York: Institute of Electrical and Electronics Engineers, 1990, p. 339.

\section{Presentations}

"Carbon Doping of GaAs, InP and Related Ternaries Using $\mathrm{CCl}_{4}$," presented at the American Conference on Crystal Growth, July 1990, Vail, Colorado.

"The Difference Between Standard and Average Efficiencies of Multijunction Cells Compared to SingleJunction Cells," presented at the 10th Photovoltaic Advanced Research and Development Review Meeting, Denver, Colorado, October 1990.
"The Effect of Growth Rate and Substrate Misorientation on the Optical Properties of $\mathrm{Ga}_{0.5} \mathrm{In}_{0.5} \mathrm{P}$," presented at the Electronic Materials Conference, Cambridge, Massachusetts, June 1990.

"The Effect of Growth Rate on the Band Gap of $\mathrm{Ga}_{0.5} \mathrm{In}_{0.5} \mathrm{P}$, Kinetics vs. Thermodynamics," presented at Texas Tech University in April 1990.

"The Effect of Growth Rate on the Properties of $\mathrm{Ga}_{0.5} \mathrm{In}_{0.5} \mathrm{P}$ Films," presented at the 8th American Conference on Crystal Growth, Vail, Colorado, July 1990.

"Growth of III-V Semiconductors Using OMVPE," guest lecture in Physics 4320, a solid state physics course, March 1990, at the University of Colorado at Boulder.

"High Efficiency GaAs Solar Cells Using GaInP 2 Window Layers," presented at the Twenty First IEEE Photovoltaic Specialists Conference, Kissimmee, Florida, May 21-25, 1990.

"Modeling of Two-Junction, Series-Connected Tandem Solar Cells Using Top-Cell and Coating Thicknesses as Adjustable Parameters," presented at the Twenty First IEEE Photovoltaic Specialists Conference, Kissimmee, Florida, May 21-25, 1990.

"Ordering and Anomalous Optical Properties of $\mathrm{Ga}_{0.5} \mathrm{In}_{0.5} \mathrm{P}$," presented at Oregon State University in January 1990 . 


\section{Section 5 Solid-State Theory}

\section{Investigators}
A. Zunger, Principal Scientist and Group Leader
S. Froyen, Senior Scientist
S.-H. Wei, Staff Scientist
R. Dandrea, OER/BES Post-Doctoral Scientist (to 11/90)
Z. W. Lu, OER/BES Post-Doctoral Scientist
R. Osorio, OER/BES Post-Doctoral Scientist
R. Magri, OER/BES Post-Doctoral Scientist (to 04/91)

\section{Objectives}

The past 10 years have seen dramatic developments and breakthroughs in theoretical physics techniques aimed at understanding, on the atomic level, the electronic structure of superconductors, metals, clusters, alloys, and other quantum behaviors that underly the properties of real materials. It is now possible to predict, from "first principles," the optical, magnetic, electrical, and thermodynamic properties of some simple materials before measurements are performed. At the same time, equally dramatic developments occurred in the laboratory with our ability to grow "artificial" crystal structures through atomic-level control of the growth process (e.g., by molecular beam epitaxy [MBE] and OMVPE). Many crystal structures, consisting of particular architectures of atomic positions (even those not present in nature) can now be grown with reasonable perfection.

The primary mission of the solid-state theory research group is to capitalize on these developments to (1) bring the state-of-the-art methods and ideas of condensed matter theory into the realm of photovoltaic materials, (2) develop a fundamental understanding of the elements that constitute and enhance solar cell performance, and (3) use this knowledge to design novel photovoltaic materials that could be grown and tested in the laboratory by modern crystal growth techniques.

A second mission is to analyze the properties of existing materials. Unlike simple devices (e.g., the transistor), solar cells are very complex in terms of their chemical constitution, diverse atomic structures, defects, interfaces, and varying degrees of order. Because of this, their performance (e.g., efficiency) depends on a very large number of material parameters that are difficult to disentangle and isolate. Our solid-state theory research attempts to address these problems by modeling the electronic structure of prototype systems that isolate these effects. This modeling includes the following:

- Defects and impurities in bulk semiconductors

- Optical properties in alloys

- The stability and thermodynamics of superlattices

- Band gaps and optical properties of novel ternary semiconductors

- The surfaces and interfaces in semiconductors

- The properties of epitaxial thin films.

This type of research involves parallel theoretical and experimental studies and is intended to ensure that photovoltaics will continuously benefit from breakthroughs achieved in other areas of condensed matter physics. This approach supplements the more conventional trial-and-error approaches to designing PV systems.

This section describes progress in this research, and work partially funded by the DOE Office of Energy Research/Basic Energy Sciences (OER/BES) is indicated as such. FY 1990 publications pertaining to this research appear in the Publications section.

\section{Major Accomplishments}

\section{Density of States of Random II-VI and III-V Semiconductor Alloys}

Many of the elements of a PV cell (either the active layer or window materials) are made of $A_{1-x} B_{x}$ alloys of some binary constituent solids $A$ and $B$. The central challenge is to describe the optical properties of $A_{1-x} B_{x}$ given those isolated properties of $A$ and $B$. We have developed a novel method of designing "special quasirandom structures" (SQS) that mimics for a small number of atoms the first few, physically most relevant radial correlation functions of an infinite, perfectly random alloy structure far better than the standard 
techniques do. Environmental effects such as correlated charge transfer and bond length relaxation are naturally included when SQSs are combined with first-principles band structure methods. We have demonstrated the usefulness of these SQSs by applying them to semiconductor alloys. Specifically, we used the SQS concept to calculate the electronic density of states (DOS), charge densities, equilibrium bond lengths, and optical bowing parameters of six random II-VI and III-V semiconductor alloys: $\mathrm{Hg}_{0.5} \mathrm{Cd}_{0.5} \mathrm{Te}$, $\mathrm{Hg}_{0.5} \mathrm{Zn}_{0.5} \mathrm{Te}, \mathrm{Cd}_{0.5} \mathrm{Zn}_{0.5} \mathrm{Te}, \mathrm{Al}_{0.5} \mathrm{Ga}_{0.5} \mathrm{As}, \mathrm{GaAs}_{0.5} \mathrm{P}_{0.5}$, and $\mathrm{Ga}_{0.5} \mathrm{In}_{0.5}$ As. We showed how different local environments around chemically identical sites lead to splitting and fine structures in the DOS, and how atomic relaxations are induced by such non-symmetric environments and lead to significant modifications in these DOS features. We found the calculated alloy bond lengths and optical bowing coefficients to be in good agreement with experiment. Cases of relaxationinduced splitting in the DOS, hitherto unobserved, are offered as predictions for future photoemission studies.

We also explored the opportunity of achieving infrared band gaps in the wavelength range above $8 \mu \mathrm{m}$ with III-V materials, using the "ordering-induced band gap narrowing" principles. We show theoretically that the recently observed spontaneous ordering of III-V alloys that yield alternate monolayer (111) superlattices provides the opportunity for achieving this goal in systems such as $(\operatorname{InAs})_{1}(\mathrm{InSb})_{1}$ and $(\mathrm{GaSb})_{1}(\operatorname{InSb})_{1}$. A substantial reduction in the direct band gap is predicted to result from L-point folding that displaces the band edge states.

\section{Stable Structures and Phase Diagrams of Intermetallic Compounds (OER/BES Work)}

Depositing A and B atoms during crystal growth could lead to a variety of structures: random alloys, ordered compounds, spontaneous superlattices, etc. The central problem is to predict, for a given A and B combination, what would be the most stable structure at low temperatures (and, therefore, what would be its properties). The diversity of possibilities is best illustrated by an example from metal physics. As elemental solids, $\mathrm{Al}, \mathrm{Ni}, \mathrm{Cu}, \mathrm{Rh}, \mathrm{Pd}, \mathrm{Pt}$, and $\mathrm{Au}$ crystallize in the fcc structure. However, at low temperatures, their $50 \%-50 \%$ compounds exhibit a range of structural symmetries: CuAu has the fccbased $L 1_{0}$ structure, CuPt has the rhombohedral $L 1_{1}$ structure, CuPd and AlNi have the body-centered cubic B2 structure, and CuRh does not exist (it phase separates into $\mathrm{Cu}$ and $\mathrm{Rh}$ ).

Phenomena-logical approaches attempt to rationalize this type of structural selectivity in terms of classical constructs such as atomic sizes, electronegativities, and electron/atom ratios. More recently, attempts have been made to explain this type of selectivity in terms of the (quantum-mechanical) electronic structure, e.g., by contrasting the self-consistently calculated total electron + ion energy of various ordered structures. Such calculations, however, normally select but a small, $O(10)$ subset of "intuitive structures" out of the $2^{\mathrm{N}}$ possible configurations (of two types of atoms on a fixed lattice with $N$ sites), searching for the lowest energy.

Instead, we used first-principles calculations of the total energies of $O(10)$ structures to define a multispin Ising Hamiltonian whose ground state structures can be systematically searched using methods of lattice theories. This is illustrated for the intermetallic compounds $\mathrm{AlNi}$, CuRh, CuPd, CuPt, and $\mathrm{CuAu}$, for which the correct ground states are identified out of some 65,000 configurations. This is done by using the density functional formalism (to extract Ising-type interaction energies) with a simple configurational search strategy (to find ground states). It establishes a direct and systematic link between the electronic structure and phase stability. By using the converged Ising interaction parameters, we were able to calculate the correct phase diagram of $\mathrm{Al}_{1-x} \mathrm{Ni}_{x}$ (for $\mathrm{x}>0.5$ ) from first principles. A ground states search reveals that the $\mathrm{PtX}(\mathrm{X}=\mathrm{Ni}, \mathrm{Cu}, \mathrm{Rh}$, and $\mathrm{Pd})$ intermetallics will form stable ordered structures at low temperatures; this is in contrast to the previous simple $d$ band tight-binding models, in which PtX will phase separate. We show that the relativistic effect in $\mathrm{Pt}$ stabilizes those compounds, while the spin-orbit effect destabilizes these compounds (instead of stabilizing them as proposed by previous theories).

\section{Spontaneous Surface-Induced Long-Range Order in GaInP Alloys}

The ternary semiconductor alloy GaInP $\mathrm{P}_{2}$ is used in high efficiency PV cells. Under certain growth conditions, it orders in a CuPt-like structure. However, the physical mechanism responsible for this is poorly understood. The band gap of $\mathrm{GaInP}_{2}$ depends strongly on the degree of order, and this affects its PV properties. Calculations by P. Faine show that a tandem cell with a top cell thickness optimized for disordered GalnP will lose $15 \%$ of its efficiency if the GaInP orders. This shows us the need to know how to control the ordering and how that ordering controls the band gap. Our current theoretical understanding suggests that neither bulk thermodynamics nor coherent epitaxial effects can explain this order and the attendant change in band gap.

To investigate a possible surface origin of the order, we used the first-principles pseudopotential method to study the energetics of several surface atomic arrangements of a single $\mathrm{GaInP}_{2}$ layer on a GaAs substrate. We allowed the atomic positions for each 
atomic arrangement to relax into an (calculated) energy-minimizing geometry. We found that among the fully relaxed, dimerized GaIn $\mathrm{P}_{2}$ surfaces, the surface corresponding to the experimentally observed CuPt-like (CP) three-dimensional order is favored over the closest competing surface (chalcopyrite) by $84 \mathrm{meV}$ per surface atom. This surface should therefore order at a growth temperature of $900 \mathrm{~K}$. Other surface arrangements have energies of $98 \mathrm{meV}$ (phase separated) and $117 \mathrm{meV}$ (CuPt with a wrong ordering vector, not seen experimentally). For similar $\mathrm{AlGaAs}_{2}$ surfaces, we do not find that a single surface arrangement of atoms is preferred, and these surfaces should therefore remain disordered. This is in agreement with experiment.

These results pertain to the surface layer on a cationterminated surface. We also considered ordering effects in deeper, buried layers. These calculations show that for a Ga/In layer immediately below an anion $(\mathrm{P})$-terminated surface, there is no ordering driving force. Using a valence force-field model, for even deeper layers, we find that $C P$ is selectively stabilized only in the third sublayer below the surface. Other layers will favor disorder and, for very deep layers, we would expect to recover the results of threedimensional epitaxial calculations. The ability of each layer to achieve its minimum energy configuration depends on the diffusion rates in each layer (which cannot be calculated by these methods). Thus, CP surface ordering can evolve to macroscopic dimensions either if a P layer immobilizes the cation layer under it or if diffusion exists up to the third subsurface layer. Finally, we verified that the model predicts the correct layer stacking for $\mathrm{CP}$ growth.

\section{Phase Transition in GaAs/Ge and GaP/Si Alloys}

Many novel optoelectronic devices are based on a combination of diamond-like materials ( $\mathrm{Si}$ or $\mathrm{Ge}$ ) and III-V materials (e.g., GaP or GaAs). Growing one with the other produces some intermixing. Our question was how we could describe the properties of such novel alloys. Single-phase semiconducting alloys made of III-V compounds (e.g., GaAs) and Column IV elemental semiconductors (e.g., Ge) constitute a new class of materials with interesting structural and optical properties. Zinc-blende-like (as in the III-V constituent) and diamond-like (as in the Column IV constituent) atomic arrangements have been detected by $x$-ray diffraction at different alloy compositions.

The Newman-Dow model was previously used to explain the observed transition between the two symmetries. It was based on the assumption of metastable bulk (three-dimensional) thermodynamic equilibrium in the distribution of the three atomic species in a fixed crystal lattice. The results of this model depended on adjustable interaction parameters between neutral atoms only. However, it is known that for corresponding III-V/IV superlattices (artificial ordered structures), charge transfer between "donor" (V-IV) and "acceptor" (III-VI) bonds is an important contribution to the formation energy.

We re-examined the validity of a bulk thermodynamic description for the III-V/IV alloys, using interaction parameters extracted from first-principles total-energy calculations for corresponding superlattices. The formation enthalpy of the superlattices was modeled by energy terms that included charge-transfer effects in addition to the interaction between neutral atoms.

We applied this energy model to two alloys (GaAs/Ge and $\mathrm{GaP} / \mathrm{Si}$ ) whose constituents have nearly equal inter-atomic distances. We found that the phase separation of the zinc-blende-like phase from the diamond-like phase (in a heterogeneous mixture) is the only stable or metastable solution of a realisticinteractions lattice model at alloy preparation temperatures (below $800 \mathrm{~K}$ ); this shows the inadequacy of bulk thermodynamic models. Therefore, singlephase samples do not correspond to the equilibrium bulk thermodynamic situation and are more likely to represent metastable surface-thermodynamic configurations.

\section{GaP/GaAs Superlattices (OER/BES Work)}

The first semiconductor superlattice to be grown artificially was $\mathrm{GaP} / \mathrm{GaAs}$, yet many of its optical properties remain unexplored, especially for shortperiod systems. First-principles pseudopotential calculations were reported for the structural properties, band offsets, and single-particle electronic states of $(\mathrm{GaP})_{n}(\mathrm{GaAs})_{n}(001)$ and (111) superlattices with $\mathbf{n} \leq 3$. With the aim of developing a systematic theory to relate superlattice levels in these ultrathin systems to those of their constituents, we treated the superlattice as evolving from a virtual-crystal parent zinc-blende compound. A semiquantitative description of the resulting superlattice states evolved from this theory. The theory is based on (1) the small perturbative nature of the superlattice ordering potential with respect to their parent compounds, (2) a generic $n$ dependence found for the intervalley coupling strengths, (3) generic selection rules governing intervalley mixing, and (4) observations of the dependence of coupling strengths on the anion versus cation character of the involved states.

Applying these principles to (110) and (201) $\mathrm{GaAs} / \mathrm{GaP}$, and to the previously studied $\mathrm{GaAs} / \mathrm{AlAs}$ systems, demonstrates their usefulness. We present calculated energy gaps (and their direct versus indirect and type-I versus type-II character) for the superlattices we studied. In addition to this study, we were interested in the possibility of designing $\mathrm{GaP} / \mathrm{GaAs}$ 
systems with a direct band gap. The bulk $\mathrm{GaAs}_{0.5} \mathrm{P}_{0.5}$ alloy with lattice constant $a(0.5)$ has an indirect band gap. First-principles self-consistent pseudopotential band structure calculations show that the monolayer $(\mathrm{GaAs})_{1}(\mathrm{GaP})_{1}$ superlattice in either the $(001)$ or the (111) layer orientation is also indirect if constrained epitaxially on a substrate whose lattice constant is $a(0.5)$. However, if grown coherently on a GaAs substrate, we predict that both of these superlattices will have a direct band gap. We explain this in terms of the deformation potentials of the underlying materials, and we give predicted band offsets for both (001) and (111) GaP/GaAs.

\section{Prediction of Formation Energies of Anti-Phase Boundaries in AlAs/GaAs (OER/BES Work)}

Certain structural defects, such as anti-phase boundaries, occur very frequently during crystal growth yet are too difficult to calculate and predict directly because of the complexity of the structure. We have developed a cluster expansion technique (see section entitled "Stable Structures and Phase Diagrams of Intermetallic Compounds") that enables us to predict formation energies of complex structures, and it requires as input first-principles calculations on a number of simple prototype structures. In Magri et al. [1990, 1991a, 1991b], we apply this method to predict the energies of (1) anti-phase boundaries in AlAs/GaAs, (2) superlattices in different stacking directions, and (3) random alloys.

\section{Publications}

\section{Publications Included in Volume II}

S. Froyen and A. Zunger, "Surface Induced Ordering in GaInP," Phys. Rev. Lett. 66, 1991, pp. 2132-2135.

J. E. Bernard, S. Froyen, and A. Zunger, "Spontaneous Surface-Induced Long-Range Order in $\mathrm{Ga}_{0.5} \mathrm{In}_{0.5} \mathrm{P}$ Alloys," Phys. Reo. B44, 1991, p. 178.

*R. G. Dandrea and A. Zunger, "First Principles Study of Intervalley Mixing: Ultrathin GaAs/GaP Superlattices," Phys. Reo. B43, 1991, pp. 8962-8989.

*R. G. Dandrea and A. Zunger, "Prediction of Direct Band Gaps in Monolayer (001) and (111) GaAs/GaP Superlattices," Appl. Phys. Lett. 57, 1990, pp. 1031-1033.

S. Froyen and A. Zunger, "Surface Reconstruction and Surface Energies of Monolayer-Coverage Cation

Terminated $\mathrm{Ga}_{0.5} \mathrm{In}_{0.5} \mathrm{P}$ (001) Surfaces," J. Vac. Sci. Tech. B9, 1991, pp. 2176-2181.
*Z. W. Lu, S.-H. Wei, A. Zunger, S. Frota-Pessoa, and L. G. Ferreira, "First-Principles Statistical Mechanics of Structural Stability of Intermetallic Compounds," Phys. Rev. B44, 1991, pp. 512-544.

*Z. W. Lu, S.-H. Wei, L. G. Ferreira, and A. Zunger, "Ground State Structures of Intermetallic Compounds: A First Principles Ising Model," Solid State Commun. 78, 1991, pp. 583-588.

*Z. W. Lu, S.-H. Wei, and A. Zunger, "Long-Range Order in Binary Late-Transition-Metal Alloys," Phys. Rev. Lett. 66, 1991, pp. 1753-1756.

R. Magri, S. Froyen, and A. Zunger, "Electronic Structure and Density of States of the Random $\mathrm{Al}_{0.5} \mathrm{Ga}_{0.5} \mathrm{As}, \mathrm{GaAs}_{0.5} \mathrm{P}_{0.5}$, and $\mathrm{Ga}_{0.5} \mathrm{In}_{0.5} \mathrm{As}$ Semiconductor Alloys," Phys. Reo. B44, 1991, p. 7947.

*R. Magri, J. E. Bernard, and A. Zunger, "Predicting Structural Energies of Atomic Lattices," Phys. Rev. B43, 1991a, pp. 1593-1597.

* $R$. Magri and A. Zunger, "Thermodynamic Instability of Ordered (001) AlGaAs, in Bulk Form," Phys. Rev. B43, 1991b, pp. 1584-1592.

${ }^{*}$ R. Magri, S.-H. Wei, and A. Zunger, "Ground-State Structures and the Random State Energy of the Madelung Lattice," Phys. Reo. B42 (Rapid Commun.), 1990, pp. 11388-11391.

R. Osorio, S. Froyen, and A. Zunger, "Structural Phase Transitions in $(\mathrm{GaAs})_{1-x} \mathrm{Ge}_{2 x}$ and $(\mathrm{GaP})_{1-x} \mathrm{Si}_{2 x}$ Alloys: Test of the Bulk Thermodynamic Description," Phys. Rev. B43, 1991, pp. 14055-14072.

R. Osorio, S. Froyen, and A. Zunger, "Superlattice Energetics and Alloy Thermodynamics of GaAs/Ge," Solid State Commun. 78, 1991, pp. 249-255.

S.-H. Wei and A. Zunger, "Proposal for III-V Ordered Alloys with Infrared Band Gaps," Appl. Phys. Lett. 58, 1991, pp. 2684-2686.

S.-H. Wei and A. Zunger, "Disorder Effects on the Density of States of the II-VI Semiconductor Alloys $\mathrm{Hg}_{0.5} \mathrm{Cd}_{0.5} \mathrm{Te}, \mathrm{Cd}_{0.5} \mathrm{Zn}_{0.5} \mathrm{Te}$, and $\mathrm{Hg}_{0.5} \mathrm{Zn}_{0.5} \mathrm{Te}$," Phys. Rev. $B 43,1991$, pp. 1662-1677.

S.-H. Wei, L. G. Ferreira, J. E. Bernard, and A. Zunger, "Electronic Properties of Random Alloys: Special Quasirandom Structures," Phys. Rev. B42, 1990, pp. 9622-9649. 


\section{Section 6 Solid-State Spectroscopy}

\section{Investigators}

\author{
A. Mascarenhas, Senior Scientist
}

\section{Objective}

The principal motivation for this research is to obtain an understanding of the fundamental optoelectronic properties of solid-state materials used for photovoltaic applications. We hope that this will provide clues to the intrinsic performance limitations of photovoltaic devices. In addition to investigating traditional photovoltaic semiconductor materials, an important aspect of this research is to explore the optical properties of novel semiconductor architectures that have a potential for photovoltaic applications. During the past year, this research focused on (1) modeling the photoluminescence of spontaneously ordered $\mathrm{GaInP}_{2}$ alloys using the formalism of quantum statistics, and (2) pioneering experiments on the optoelectronic properties of novel spinodally decomposed semiconductor alloys.

In addition to these areas, a significant amount of time was spent expanding the experimental capabilities of the laboratory for solid-state spectroscopy. The laboratory was extended to include additional floor space for new experimental setups. We set up an ultra-low-noise, charge-coupled-device (CCD)-based array detector coupled to a high-resolution spectrograph for very rapid photoluminescence and Raman scattering experiments.

\section{Major Accomplishments}

\section{Modeling the Photoluminescence of Spontaneously Ordered $\mathrm{GaInP}_{2}$}

Our investigations into the polarized photoluminescence of spontaneously ordered $\mathrm{GaInP}_{2}$ yielded the first experimental evidence of the spontaneous breaking of cubic symmetry in the band structure of this alloy. Initially, qualitative physical arguments [Mascarenhas et al., 1990] were used to explain the nature of photoluminescence in the spontaneously ordered alloy. Because the phenomenon of spontaneous ordering has recently been observed in several other III-V alloy systems, each of which exhibits a unique symmetry in the ordered form, there was a need for a generalized approach to understanding the effects of symmetry breaking on the photoluminescence of ordered alloys. With this in mind, and to provide a more quantitative description of the photoluminescence observed in $\mathrm{GaInP}_{2}$, we used the formalism of quantum statistics [Mascarenhas and Olson, 1990] to analyze photoluminescence polarization in this spontaneously ordered alloy.

\section{Pioneering Experiments on the Optoelectronic Properties of Novel Spinodally Decomposed Semiconductor Alloys}

We recently studied a $(\mathrm{GaP})_{2} /(\mathrm{InP})_{2}$ superlattice grown on a [001] GaAs substrate. The results of the NREL experiments provided the first experimental demonstration of the optoelectronic properties of a spontaneously generated lateral superlattice. Here we will briefly outline the dynamics of the phenomenon of spontaneous lateral composition modulation. We propose that this phenomenon can be a new tool for tailoring the optoelectronic properties of semiconductor alloys.

In a recent experiment at the University of Illinois [Hsieh et al., 1990], a $(\mathrm{GaP})_{2} /(\mathrm{InP})_{2}$ bilayer superlattice (BSL) was successfully grown on a GaInP $P_{2}$ buffer layer deposited on a (001) GaAs substrate by MBE. Using TEM, transmission electron diffraction (TED), energy dispersive $x$-ray microanalysis, and double crystal $x$-ray rocking curves, the investigators verified the composition and structure of the buffer and the BSL. In addition, they observed an unintentional lateral compositional modulation of the BSL along the [110] direction. Using cathodoluminescence studies, they reported band-gap lowerings of 130 and $37 \mathrm{meV}$ for the BSL and buffer layer, respectively (compared to the random alloy $\mathrm{GaInP}_{2}$ ). They inferred that the reduction in the band gaps was caused by the ordered bilayer structure of the BSL and by the weak CuPt-type ordering in the buffer layer. However, A. Zunger at NREL pointed out that the $130 \mathrm{meV}$ band-gap lowering observed in the BSL was inconsistent with theoretical predictions that $\mathrm{CuAu}$-type ordering (ordering axis along $<001>$ ) leads to a much smaller band-gap reduction than does CuPt type ordering (ordering axis along $<111>$ ). To resolve this anomaly, A. Mascarenhas examined the Illinois-grown samples 
at NREL using low-temperature polarized photoluminescence techniques. The results of these studies are shown in Figure 6-1 and are astonishing. The direction of asymmetry is the BSL growth direction, [001]. Therefore, for the photoluminescence spectra, no asymmetry between the [110] and [110] directions is anticipated because both of these directions lie in the epitaxial growth plane, a symmetry plane of the BSL. Evidently, the optoelectronic properties of the BSL are governed not by the vertical [001] bilayer ordering but rather by the lateral [110] composition modulation that had occurred spontaneously during growth. Using group theoretical methods, we verified that the asymmetry in the photoluminescence was caused by selection rules for electronic transitions in such a laterally modulated structure. This was the first experimental demonstration of the optoelectronic properties of a spontaneously generated lateral superlattice.
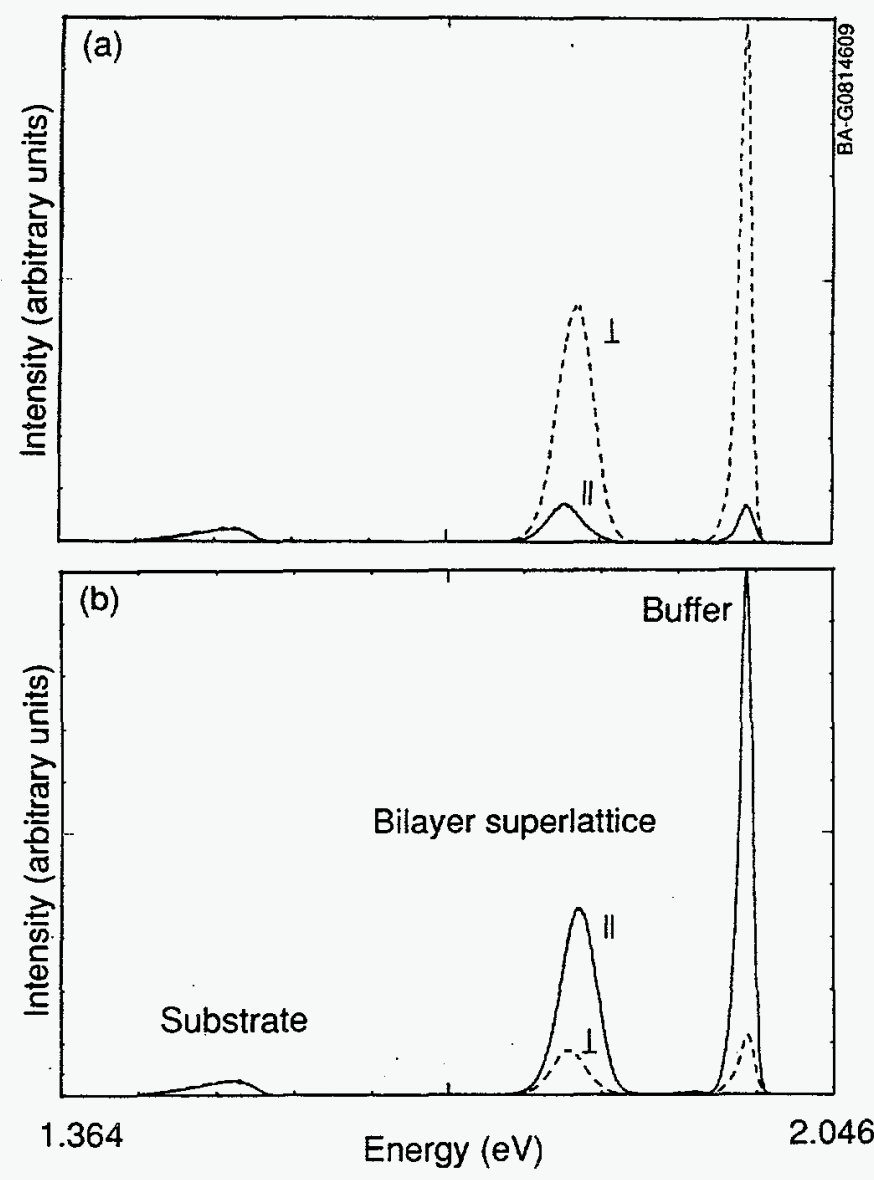

Figure 6-1. Low-temperature (15 $\mathrm{K}) \mathrm{PL}$ spectra from the sample excited with light polarized perpendicular to the modulation (a) and parallel to the modulation (b). The PL is measured for polarization parallel (II) and perpendicular ( $\perp$ ) to that of the incident light.
These results have profound implications for the materials science of alloy semiconductor heterostructures and the design of novel architectures for optoelectronic device applications. Since the first proposal for an artificially generated man-made superlattice [Esaki and Tsu, 1970], there has been an explosion of research activity on the materials science, physics, and device technologies based on generating vertical superlattices using epitaxial layer growth techniques such as MBE and OMVPE. In contrast, despite the enormous technological potential of lateral superlattice architectures, research progress in this area has been almost insignificant. This is because the complexity of generating lateral superlattices has made such a task almost infeasible.

We now propose that spontaneous composition modulation (as exhibited in the Illinois-grown BSL) can be used as a new technique for generating lateral superlattice architectures. Intrinsically related to the phenomenon of spontaneous ordering, the phenomenon of spontaneous composition modulation is a complementary process. We emphasize this point as the most significant distinction from all current (as well as future BES-funded) NREL work on spontaneous ordering. Next, we will briefly outline our current views on the physical mechanisms that govern the dynamics of such a process.

Almost a decade ago, it was quite a puzzle. A miscibility gap was predicted at the usual growth temperatures for liquid phase epitaxy (LPE) of the quartenary alloy $\operatorname{In}_{1-x} G_{x} A_{s_{y}} P_{1-y}$, but high-quality films of this material could regularly be obtained by LPE on lattice-matched InP substrates. Some argued that the solid solution was stabilized by the substrate-induced strain [DeCremoux et al., 1980]. When the strain effect was relaxed by growing intentionally unmatched layers, phase separation clearly occurred [Quillec et al., 1982]. Later, using TEM studies, Henoc et al. (1982) reported a strain contrast with a periodicity of $1000 \AA$ in the $<100>$ and $<010>$ directions for $\mathrm{In}_{1-x} \mathrm{Ga}_{\mathrm{x}} \mathrm{As}_{\mathrm{y}} \mathrm{P}_{1-\mathrm{y}}$ alloy compositions. The compositions were within the miscibility gap and were lattice matched to (001) InP substrates; Henoc suggested spinodal decomposition at the liquid/solid interface as the possible explanation. These studies were later corroborated by Norman and Booker (1985).

As a very separate issue, during the past six years there have been several experimental reports [Wei and Zunger, 1989] of spontaneous ordering in epitaxially grown alloys of $\mathrm{AlGaAs}_{2}, \mathrm{InGaAs}_{2}, \mathrm{GaInP}_{2}, \mathrm{Ga}_{2} \mathrm{AsSb}$, and $\mathrm{Ga}_{2} \mathrm{AsP}$, to name a few. These results corroborated the theoretical predictions of A. Zunger's group at NREL about the existence of ordered phases that are more stable than the random disordered phase of several pseudobinary semiconductor alloys. In a recent study on epitaxially grown GaInP ${ }_{2}$, Froyen and Zunger 
(1991) showed that spontaneous ordering in the alloy is surface-driven, and that surface reconstruction must be taken into account in determining the choice of the ordered phase.

Ueda et al. (1989) used TEM studies and Okuda et al. (1990) used X-ray diffraction studies and both groups observed the presence of composition modulation in OMVPE-grown films of $\mathrm{GaInP}_{2}$ lattice matched to (001) GaAs substrates. The simultaneous presence of both spinodal decomposition and spontaneous long-range ordering in Group III-V semiconductor alloys is not predicted by thermodynamics using the regular solution approximation [Stringfellow, 1974]. A positive enthalpy of mixing $\Delta \mathrm{H}$ is expected to favor spinodal decomposition of the alloy, whereas a negative $\Delta \mathrm{H}$ is expected to favor ordering. However, although the regular solution model predicts that spinodal decomposition and long-range spontaneous ordering are mutually exclusive, there have been observations of spinodal decomposition in alloys that also exhibit spontaneous ordering. In a detailed in-situ reflection high-energy electron diffraction (RHEED) study of $\mathrm{GaAs}_{1-\mathrm{y}} \mathrm{Sb}_{\mathrm{y}}$ grown by MBE on (001) GaAs substrates, Murgatroyd et al. (1990) observed the simultaneous presence of CuPt-type spontaneous ordering and composition modulation along the [110] direction, and they presented a model to show that they are both a direct consequence of the surface reconstruction. In a separate study on InGaAsP grown by LPE lattice matched to InP substrates, McDevitt et al. (1990) concluded that the phase separation observed in their samples was two-dimensional (phase separation was observed along the soft directions lying in the growth plane) and did not occur along the growth direction. They inferred that phase separation and ordering occur concomitantly at the surface while the layer is growing.

These experimental results are paradoxically at odds with those of the regular solution model. However, a more recent study by A. Zunger's group [Wei et al., 1990] showed that if the thermodynamic properties of bulk isovalent zinc-blend alloys are modeled using a generalized Ising model with up to fourth-neighbor interactions, then alloys with $\Delta \mathrm{H}>0$ can show phase separation when size-matched or metastable long-range spontaneous ordering when size-mismatched. In the case of the $(\mathrm{GaP})_{2} /(\operatorname{InP})_{2}$ BSL grown by the Illinois group, there is a large lattice mismatch $(8 \%)$ between the two binary components. The bilayer $<001\rangle$ superlattice $(\mathrm{GaP})_{2} /(\operatorname{InP})_{2}$ is predicted to be unstable with regard to disproportionation into its bulk binary constituents [Dandrea et al., 1990]. In the Illinoisgrown $(\mathrm{GaP})_{2} /(\mathrm{InP})_{2} \mathrm{BSL}$, the vertical [001] ordering is achieved not spontaneously but with the assistance of the external driving force of MBE. However, because of the inherent instability of this [001] ordered BSL and the lattice mismatch of the binary constituents, the structure exhibits spinodal decomposition in the [110] direction. We believe that the spontaneous lateral composition modulation in the growth plane is the channel through which the instability in the [001] ordered BSL is relaxed.

\section{Publications and References}

\section{Publications Included in Volume II}

A. Mascarenhas, Sarah Kurtz, A. Kibbler, and J. M. Olson, "Optical Investigations of Symmetry Breaking in $\mathrm{GaInP}_{2}$ " in Epitaxial Heterostructures, R. Tung, L. R. Dawson, and R. L. Gunshor, eds., MRS Symposia Proceedings 198, 1990, p. 65.

A. Mascarenhas and J. M. Olson, "Quantum Statistics of Polarized Photoluminescence in Ordered GaInP ${ }_{2}$," Phys. Rev. B41, May 1990, p. 9947.

\section{Other Publications}

R. G. Dandrea, J. E: Bernard, S.-H. Wei, and A. Zunger, "Stability of Coherently Strained Semiconductor Superlattices," Phys. Reo. Lett. 64, January 1990, p. 36.

B. DeCremoux, P. Hirtz, and J. Ricciardi, "On the Presence of a Solid Immiscibility Domain in the GaInAsP Phase Diagram," in GaAs and Related Compounds, Vienna, 1980, H. W. Thim, ed., Inst. Phys. Conf. Ser. 56, 1980, p. 115.

L. Esaki and R. Tsu, "Superlattice and Negative Differential Conductivity in Semiconductors," IBM J. Res. Dev. 14, 1970, p. 61.

S. Froyen and A. Zunger, "Surface-Induced Ordering in GaInP," Phys. Reo. Lett. 1991, p. 2132.

P. Henoc, A. Izrael, M. Quillec, and H. Launois, "Composition Modulation in Liquid-Phase Epitaxial In $\mathrm{Ga}_{1-\mathrm{x}} \mathrm{As}_{\mathrm{y}} \mathrm{P}_{1-\mathrm{y}}$ Layers Lattice Matched to InP Substrates," Appl. Phys. Lett. 40, June 1982, p. 963.

K. C. Hsieh, J. N. Baillargeon, and K. Y. Cheng, "Compositional Modulation and Long-Range Ordering in GaP/InP Short Period Superlattices Grown by Gas Source Molecular Beam Epitaxy," Appl. Phys. Lett. 57, November 1990, p. 21.

T. L. McDevitt, S. Mahajan, D. E. Laughlin, W. A. Bonner, and V. G. Keramidas, "Surface Phase Separation and Ordering in Compound Semiconductor Alloys," Materials Research Society Symposium Proceedings, Vol. 198, Pittsburgh, Pennsylvania: Materials Research Society, 1990, p. 609.

I. J. Murgatroyd, A. G. Norman, and G. R. Booker, "Observation of [111\} Ordering and [110] Modulation 
in Molecular Beam Epitaxial $\mathrm{GaAs}_{1-\mathrm{y}} \mathrm{Sb}_{\mathrm{y}}$ Layers: Possible Relationship to Surface Reconstruction Occurring During Layer Growth," J. Appl. Phys. 67, March 1990, p. 2310.

A. G. Norman and G. R. Booker, "Transmission Electron Microscope and Transmission Electron Diffraction Observations of Alloy Clustering in LiquidPhase Epitaxial (001) GaInAsP Layers," J. Appl. Phys. 57, May 1985, p. 4715.

H. Okuda, M. Kondo, K. Kato, and K. Nakajima, "X-ray Observation of Compositional Modulation Caused by Phase Decomposition in GaInP Ternary Alloys," Appl. Phys. Lett. 56, January 1990, p. 337.

M. Quillec, C. Daguet, J. L. Benchimol, and H. Launois, "In $\mathrm{Ga}_{1-\mathrm{x}} A \mathrm{~s}_{\mathrm{y}} \mathrm{P}_{1-\mathrm{y}}$ Alloy Stabilization by the InP Substrate Inside an Unstable Region in Liquid Phase Epitaxy," Appl. Phys. Lett. 40, 1982, p. 325.
G. B. Stringfellow, "Calculation of Ternary and Quaternary Phase Diagrams," J. Cryst. Growth 27, 1974, pp. 21-34.

O. Ueda, M. Takechi, and J. Komeno, "Generation of Strong Composition-Modulated Structures and Absence of Ordered Structures in InGaP Crystals Grown on (110) GaAs Substrates by Metal Organic Chemical Vapor Deposition," Appl. Phys. Lett. 54, June 1989, p. 2312.

S.-H. Wei, L. G. Ferreira, and A. Zunger, "FirstPrinciples Calculation of Temperature-Composition Phase Diagrams of Semiconductor Alloys," Phys. Rev. B41, April 1990, p. 8241.

S.-H. Wei and A. Zunger, "Band Gaps and Spin-Orbit Splitting of Ordered and Disordered $\mathrm{Al}_{\mathrm{x}} \mathrm{Ga}_{1-\mathrm{x}} \mathrm{As}$ and $\mathrm{GaAs}_{\mathrm{x}} \mathrm{Sb}_{1-\mathrm{x}}$ Alloys," Physical Review B39, February 1989, p. 3279. 


\begin{tabular}{|c|c|c|c|}
\hline $\begin{array}{c}\text { Document Control } \\
\text { Page }\end{array}$ & $\begin{array}{l}\text { 1. SERI Report No. } \\
\text { NREL/TP-212-4431 }\end{array}$ & $\begin{array}{l}\text { 2. NTIS Accession No. } \\
\text { DE92001210 }\end{array}$ & 3. Recipient's Accession No. \\
\hline \multirow{2}{*}{\multicolumn{3}{|c|}{$\begin{array}{l}\text { 4. Title and Subtitle } \\
\text { Annual Report, Basic Sciences Branch, FY } 1990\end{array}$}} & $\begin{array}{l}\text { 5. Publication Date } \\
\text { December } 1991\end{array}$ \\
\hline & & & 6. \\
\hline \multicolumn{3}{|c|}{$\begin{array}{l}\text { 7. Author(s) } \\
\text { Basic Sciences Branch }\end{array}$} & 8. Performing Organization Rept. No. \\
\hline \multirow{2}{*}{\multicolumn{3}{|c|}{$\begin{array}{l}\text { 9. Performing Organization Name and Address } \\
\text { National Renewable Energy Laboratory } \\
1617 \text { Cole Blvd. } \\
\text { Golden, Colorado } 80401-3393\end{array}$}} & $\begin{array}{l}\text { 10. Project/Task/Work Unit No. } \\
\text { PV211201 }\end{array}$ \\
\hline & & & $\begin{array}{l}\text { 11. Contract (C) or Grant (G) No. } \\
\text { (C) } \\
\text { (G) }\end{array}$ \\
\hline \multirow{2}{*}{\multicolumn{3}{|c|}{ 12. Sponsoring Organization Name and Address }} & $\begin{array}{l}\text { 13. Type of Report \& Period Covered } \\
\text { Progress Report }\end{array}$ \\
\hline & & & 14. \\
\hline \multicolumn{4}{|c|}{ 15. Supplementary Notes } \\
\hline \multicolumn{4}{|c|}{ 16. Abstract (Limit: 200 words) } \\
\hline \multicolumn{4}{|c|}{$\begin{array}{l}\text { This report summarizes the progress of the Basic Sciences Branch of the National Renewable Energy Laboratory } \\
\text { (NREL) from October } 1,1989 \text {, through September } 30,1990 \text {. Six technical sections or the report cover these main } \\
\text { areas of NREL's in-house research: Semiconductor Crystal Growth, Amorphous Silicon Research, Polycrystalline } \\
\text { Thin Films, III-V High-Efficiency Photovoltaic Cells, Solid-State Theory, and Solid-State Spectroscopy. Each } \\
\text { section explains the purpose and major accomplishments of the work in the context of the U.S. Department of } \\
\text { Energy's National Photovoltaic Research Program plans. }\end{array}$} \\
\hline \multicolumn{4}{|c|}{$\begin{array}{l}\text { 17. Document Analysis } \\
\text { a. Descriptors } \\
\text { solar cells ; semiconductors ; annual report ; research and development ; photovoltaics } \\
\text { b. Identifiers/Open-Ended Terms }\end{array}$} \\
\hline \multicolumn{4}{|l|}{$\begin{array}{l}\text { c. UC Categories } \\
270\end{array}$} \\
\hline \multirow{2}{*}{\multicolumn{2}{|c|}{$\begin{array}{l}\text { 18. Availability Statement } \\
\text { National Technical Information Service } \\
\text { U.S. Department of Commerce } \\
\text { 5285 Port Royal Road } \\
\text { Springfield, VA } 22161\end{array}$}} & & $\begin{array}{l}\text { 19. No. of Pages } \\
47\end{array}$ \\
\hline & & & $\begin{array}{l}\text { 20. Price } \\
\text { A03 }\end{array}$ \\
\hline
\end{tabular}

Form No. 0069E (6-30-87) 